\title{
Los laberintos de la justicia transicional en Uruguay (1985-2019)
}

\author{
Andrés del Río Roldán* \\ Si me dieran a elegir, yo elegiría \\ esta salud de saber que estamos muy enfermos, \\ esta dicha de andar tan infelices. \\ Si me dieran a elegir, yo elegiría \\ esta inocencia de no ser un inocente, \\ esta pureza en que ando por impuro. \\ Si me dieran a elegir, yo elegiría \\ este amor con que odio, \\ esta esperanza que come panes desesperados. \\ Aquí pasa, señores, \\ que me juego la muerte. \\ El juego en que andamos \\ Juan Gelman
}

\section{$\boldsymbol{R}$}

\section{esumen}

La investigación y sanción de las violaciones de los derechos humanos de las dictaduras en los países de la región América Latina se ha convertido en un tema inevitable para el fortalecimiento y la consolidación de las democracias de la región. En el presente trabajo, observaremos los principales eventos en el proceso de justicia transicional (JT)en Uruguay desde la redemocratización hasta nuestros días (1985-2019).

Analizaremos los principales acontecimientos observando la participación de (y en) los tribunales en el proceso de lucha por la memoria, la verdad y la justicia. También examinaremos la posición de cada uno de los gobiernos sobre la revisión del pasado reciente. El estudio intenta colaborar en el debate actual sobre los procesos de revisión del pasado reciente violento en nuestra región, desde la perspectiva de la justicia transicional, enfatizando la trayectoria de los tribunales y la posición de los gobiernos en el poder en relación con la impunidad.

Palabras clave: Justicia Transicional, Ley de Caducidad, Dictadura, Suprema Corte de Justicia, Uruguay

\section{Abstract}

\section{The Labyrinths of Transitional Justice in Uruguay (1985-2019)}

The investigation and punishment for violations of the human rights of dictatorships in Latin America have become an unavoidable issue for the strengthening and consolidation of democracies in the region. In this paper, we will observe the major events in the transitional justice (TJ) process in Uruguay since democracy until the present day (1985-2019).

We will analyze the main events observing the participation of (and in) the courts in the struggle for memory, truth and justice. We will also examine the position

\footnotetext{
Investigador visitante en ITESO, Guadalajara. Es profesor adjunto de Ciencias Políticas en la Universidad Federal Fluminense (UFF), Rio de Janeiro. Investigador permanente del Instituto Nacional de Ciencia y Tecnología, del Programa de Políticas Públicas, Estrategia y Desarrollo INCT-PPED, IESP-UERJ. Vice Jefe del Departamento de Geografía y Políticas Públicas DGP-IEAR-UFF. Y Coordinador del Núcleo de Estudios sobre Estado, Instituciones y Políticas Públicas, NEEIPP de UFE_Contacto:andres.delrio@gmail.com
} 
on the review of the violent past in each of the governments. The study attempts to collaborate in the current debate about the processes of review the violent past in our region, from the perspective of transitional justice, emphasizing the trajectory of the courts and the position of the governments in power with respect to impunity.

Keywords: transitional Justice, Expiry Law, Dictatorship, Supreme Court, Uruguay

\section{Una aproximación al contexto}

Actualmente, Uruguay está atravesando plena campaña electoral para presidente y renovación parlamentaria. La Frente Amplia lidera la intención de voto, aunque muy posiblemente tenga que ir a una segunda vuelta -después de 15 años continuos en el poder, comienzan a lidiar con el desgaste producido de estar tanto tiempo al frente-. La novedad en este escenario proviene del ámbito internacional y doméstico. Por un lado, gobiernos de derechas fueron alcanzando el poder en América del Sur, estos gobiernos demostraron gestiones erráticas en las cuestiones sociales y económicas: la desigualdad, desempleo y violencia aumentó sensiblemente en los últimos años; mismo así, estos gobiernos han parecido afines a políticas de seguridad interna, buscando incorporar a los sectores militares en sus planes. Por su parte, en el ámbito doméstico, la extrema derecha y pautas conservadoras fueron ganando terreno en las discusiones locales durante la campaña electoral. En este sentido, el Bolsonaro local, Manini Rio, del partido Cabildo Abierto, declaró a los cuatro vientos su desacuerdo con la revisión del pasado violento reciente. La JT en Uruguay va sintiendo los desafíos al ritmo internacional y local.

\section{Una aproximacion al caso Uruguay}

Reconciliar los dolores del pasado marcado por las violaciones de los derechos humanos, como ocurrió en el Cono Sur, con las dictaduras de los años setenta y ochenta, no es una tarea fácil. Las dictaduras en la región trajeron años oscuros de horror y dolor, en los que América Latina conoció de terrorismo de Estado instrumentalizado a partir de la Doctrina de Seguridad Nacional y la Operación Cóndor. ${ }^{\mathrm{i}}$
La investigación y sanción de los crímenes de las dictaduras en los países latinoamericanos se ha convertido en un tema inevitable para el fortalecimiento y la consolidación de las democracias en la región. La lucha por la memoria, la verdad y la justicia ha sido tortuosa y prolongada, con trayectorias y resultados muy diferentes.

En las democracias donde se dió este tipo de régimen, el tema de la llamada JT ha sido abordado con diferentes soluciones de acuerdo a las particularidades de cada país. Cada nación enfrenta su pasado violento de acuerdo a sus posibilidades, estructuras institucionales, movimientos sociales y políticos. Así, se gestiona un frágil equilibrio en función de los diferentes sectores y de la diversidad de demandas de cada escenario nacional. En el proceso, la reconciliación no tiene el mismo significado para todos los miembros de la sociedad. El Poder Judicial tiene un papel fundamental en la materialización de la justicia y el castigo, pero no siempre forma parte de los sectores que desean revisar el pasado, o bien, no tiene una actitud proactiva respecto a la búsqueda de la verdad y el castigo. La justicia es otro espacio para la lucha política, la negociación en la reconciliación y la reconstrucción. De esta manera, la justicia puede ser un actor importante en la revisión o un límite en la búsqueda de la verdad.

En los doce años en los que la dictadura permaneció en Uruguay (1973-1985), el país se destacó por su práctica sistemática de la tortura, el encarcelamiento prolongado, el fuerte control a la prensa y los medios de comunicación, el límite a la creación de todo tipo de asociaciones, el cerco a la educación, al deporte y a la cultura. Pero la principal dimensión represiva del régimen dictatorial uruguayo fue el encarcelamiento masivo y prolongado.

\section{Cuadro 1}

Transgresiones comunes de las dictaduras

\begin{tabular}{llll}
\hline - Violación de derechos & - Uso masivo de la tortura & - & $\begin{array}{l}\text { Censura y nula libertad de } \\
\text { expresión } \\
\text { humanos }\end{array}$ \\
- Desapariciones & - Secuestro de niños & $\begin{array}{l}\text { Condena de cientos de } \\
\text { ciudadanos al exilio }\end{array}$ \\
- Asesinatos & - Imposición del miedo & \begin{tabular}{l} 
como politica diaria \\
\hline
\end{tabular}
\end{tabular}

Autoría propia 
Con un universo de casi 6.000 presos políticos entre 1973 y 1984, el método de encarcelamiento estaba directamente relacionado con la aplicación generalizada y sistemática de la tortura a los detenidos, esta marca carcelaria tiene que ver con el carácter de la dictadura uruguaya, más del tipo policial que militar (Rico, 2009: 151). Como indica Caetano (2015: 159), Uruguay fue una gran prisión: en 1976, el país tenía la tasa más alta de presos políticos per cápita de América Latina.

Ante este panorama histórico, Uruguay ha abierto un proceso de revisión del pasado con sus propias particularidades: estableció una nueva legislación nacional e incorporó legislación internacional, implementó comisiones, elaboró informes, tanto públicos como de la sociedad civil, realizó juicios aislados, promovió un referéndum y un plebiscito, sancionó una ley interpretativa, pero el alma de ley de amnistía -cuerpo normativo aún anquilosado en el pasado-, sigue vigente.

La ley de amnistía otorgó al Poder Ejecutivo poderes exclusivos para decidir el futuro de las investigaciones. El Poder Judicial permaneció a la sombra de esta ley, sin aprovechar durante mucho tiempo las lagunas que tenía. En el nuevo milenio, la lucha se trasladó gradualmente a la esfera judicial. Pero este cambio no significó grandes resultados, ni consolidados ni homogéneos. Por el contrario, en el Poder Judicial, las barreras técnicas hicieron imposible lograr resultados significativos. Y estas barreras se configuran como una continuidad de la impunidad.

A partir de una trayectoria intermitente y sin ruptura sustancial, hoy no es posible entender la JT en el Uruguay sin observar los movimientos de (y en) los tribunales, y la actividad existente desde las organizaciones de derechos humanos, base principal de la JT en el país. En este documento, describiremos brevemente los principales acontecimientos del proceso de JT uruguayo hasta la fecha, destacando las actitudes de los tribunales. También examinaremos la posición sobre la revisión del lento pasado de cada uno de los gobiernos en el período seleccionado (19852019). En Uruguay, el terrorismo de Estado todavía sigue siendo un proceso de comprensión y revisión.

\section{La Justicia de Transición y los tribunales}

La Justicia de Transición surge como una respuesta concreta a las violaciones sistemáticas de los derechos humanos en un pasado no democrático y traumático. Es un término genérico que abarca una amplia gama de prácticas diferentes (Comisiones de la verdad, Tribunales, reparaciones, amnistías, indultos, entre otros) y genera mucho debate en el ámbito académico. Su concepción fue delimitada por el Consejo de Seguridad de las Naciones Unidas (UN Security Council, 2004), y es una definición suficientemente amplia para cubrir las diversas formas de JT que se desean. En pocas palabras, Paul Van Zyl indica:

El objetivo de la justicia transicional es procesar a los perpetradores, revelar la verdad sobre los crímenes del pasado, proporcionar reparaciones a las víctimas, reformar las instituciones abusivas y promover la reconciliación. Lo que se ha mencionado anteriormente requiere un conjunto inclusivo de estrategias formuladas para abordar el pasado, así como para mirar hacia el futuro a fin de evitar la reaparición de conflictos y violaciones. (...) las estrategias de la justicia transicional se diseñan en contextos en los que la paz es frágil o en los que los perpetradores conservan un poder real, hay que equilibrar cuidadosamente las exigencias de la justicia y la realidad de lo que se puede hacer a corto, mediano y largo plazo. (Van Zyl, 2009: 32-33).

La JT tiene cuatro dimensiones principales: la reparación a las víctimas, la búsqueda de la verdad y la construcción de la memoria, la reforma de las instituciones del Estado y el restablecimiento de la igualdad de las personas ante la ley. Según el Centro Internacional para la Justicia Transicional (ICTJ: 2010): "ninguna medida es tan eficaz como todas ellas combinadas". Olsen, Payne y Reiter por su parte reconocen que:

A pesar de que las medidas de justicia transicional se basan en sólidas obligaciones legales y morales, existe una amplia libertad en cuanto a cómo se pueden cumplir estas obligaciones y, por lo tanto, no existe una fórmula que se ajuste a todos los contextos (2009: 166).

Los estudios sobre JT tienen una interdisciplinariedad intrínseca al objeto de estudio. Es un área muy compleja de estudios del Derecho, la Sociología, la Historia, y las Ciencias Políticas, entre otras. Las diferentes dimensiones de la JT se elaboran de las maneras más diversas. Pero en relación con la dimensión de la igualdad ante la ley, no hay muchos estudios que se centren en la participación de los tribunales en este proceso de revisión y sanción del pasado violento. Los sistemas de justicia no siempre participan activamente en el proceso, juzgar a los represores es una parte crítica de la JT. La continuidad institucional, sobre todo en el ámbito judicial, forma parte de los retos que debe afrontar la democracia. Como indica el documento del Consejo de Seguridad de las Naciones Unidas (ONU, 2011: 9):

Los sistemas nacionales de justicia en el proceso de justicia transicional generalmente no han llevado a cabo reformas institucionales y presentan imposibilidades estructurales y de recursos humanos para reconocer los complejos casos de violaciones masivas de los derechos humanos. 
La JT en Uruguay tiene sus propias etapas, en un inicio con fuertes políticas de impunidad, hasta la actual lucha incierta y poco homogénea en el ámbito judicial. Desde el principio, la intención era hacer del silencio una llave, hay quienes creyeron que esto aseguraría un futuro de paz, pero como lo indica el Informe Uruguay Nunca Más (SERPAJ, 1989: 274): "los hechos, las víctimas, están allí, y hablan o gritan por sí mismos. Y no hay futuro si pretendemos hacer oídos sordos a lo que ellos expresan". Los logros que se pueden alcanzar con la JT trascienden a las víctimas individuales para involucrar a la sociedad como una víctima más de las violaciones durante la dictadura. Por lo tanto, el JT excede el juicio individual para interesar a todos los individuos (Mota, 2016: 2).

\section{Con la democracia en el horizonte}

En 1984, Uruguay ya estaba en camino de establecer las condiciones y acuerdos para una transición democrática. Por un lado, el Partido Nacional no aceptó las condiciones que se proponían -su líder, Wilson Ferreira, fue finalmente arrestado y encarcelado-. Por otro lado, el Partido Colorado, liderado por Julio Sanguinetti, entendió la necesidad de negociar con los militares para poner fin a la dictadura.

Las negociaciones terminaron con el Acuerdo del Club Naval el 3 de agosto de 1984. Los dirigentes políticos de los partidos Colorado, Frente Amplia y, en menor medida, la Unión Cívica, además de la cúpula castrense, participaron en las negociaciones, con un contenido confidencial. El Partido Nacional no formó parte del acuerdo. Según este, las elecciones se celebrarían en noviembre de 1984, momento en el cual sería posible garantizar la participación de otros partidos que anterior al acuerdo habían sido incapacitados o prohibidos. Cabe señalar que el principal dirigente del Partido Nacional, Wilson Ferreira Aldunate, ya estaba en prisión y que el principal dirigente del Frente Amplio, el General Liber Ceregni, fue vetado, así como el Partido Comunista (Uruguay Nunca Más, 1989: 58; Michelini, 1996: 159) fue impedido de competir. Pero más allá de las especificidades electorales, las condiciones establecidas sobre el futuro gobierno demostraron la fuerza que aún tenía el poder militar.

Con el lema Cambio pela paz, el líder del Partido Colorado, Julio Sanguinetti, fue elegido presidente. Representó a los sectores de oposición más moderados del centro, su proyecto político no excluía a los militares del proceso, respetando su parte de poder. Sin embargo, esta transición, condicionada y protegida por el poder militar, tuvo un impacto y consecuencias en el retorno a la democracia. Específicamente sobre los temas de la responsabilidad por las violacio- nes de los derechos humanos en el pasado reciente, y la lucha por la memoria, la verdad y la justicia.

\section{Forzar el olvido: la primera presidencia de San- guinetti (1985-1990)}

El primer día de marzo de 1985 Sanguinetti asumió la presidencia de Uruguay, dando inicio a la alternancia de dos décadas en el poder entre el Partido Colorado y el Partido Nacional.

Con el retorno democrático, se abrió la esperanza en los sectores de la defensa de los derechos humanos. Creció la expectativa de conocer la verdad a través de la justicia, identificar a los responsables, conocer el destino de las personas desaparecidas, abrir archivos y encontrar menores secuestrados. Pero en el camino hacia la restauración de la democracia, la supuesta pacificación se convirtió en el valor supremo de la transición uruguaya en detrimento de otros valores fundamentales como la verdad, la reparación y la justicia (Galain Palermo, 2009: 398).

El retorno a la democracia fue recibido con dos leyes de amnistía, entre otras. ${ }^{\text {ii }}$ La primera de ellas, conocida como la Ley Nacional de Pacificación, fue la Ley 15.737, de marzo de 1985, promulgada por el Parlamento. Con ella se proclamó la amnistía para los actores de los crímenes políticos (o relacionados con crímenes políticos) cometidos desde el 1 de enero de 1962. El artículo 5 de esta ley excluye expresamente de la amnistía los delitos cometidos por personal policial y militar en el ejercicio de sus funciones; no obstante, nadie fue encarcelado en ese momento por esas razones. Es importante destacar que la ley en su artículo primero no amnistía a los autores de delitos de homicidio doloso. ${ }^{\text {iii }}$

Un paso a ser destacado, y con consecuencias para el futuro de la JT, fue la incorporación en esta ley, en el artículo 15, la ratificación de la Convención Americana sobre Derechos Humanos y en el artículo 16 se reconoció la competencia de la Comisión y la jurisdicción de la Corte Interamericana de Derechos Humanos. ${ }^{\text {iv }}$

Los sectores afectados de la sociedad no esperaron y acudieron a los tribunales para reclamar los derechos humanos violados durante la dictadura. En estas primeras demandas (aproximadamente 20), la justicia militar reclamó para sí la jurisdicción y competencia. En un extenso proceso de luchas políticas, finalmente y a pesar de la demora, la Corte Suprema de Justicia (SCJ) indicó que era competencia de la justicia ordinaria. Así, la lucha en los tribunales comenzó a mostrar las características de una lucha que se volvería compleja. 
Como parte del restablecimiento del parlamento uruguayo, en abril de 1985 se formaron dos comisiones especiales de investigación. La primera fue la "Comisión Investigadora sobre el Secuestro y Asesinato perpetrados contra los ex legisladores Héctor Gutiérrez Ruiz y Zelmar Michelini”. Su objetivo era investigar los asesinatos de los legisladores que dieron nombre a la comisión, el 20 de mayo de 1976 en Buenos Aires, Argentina. El 13 de octubre de 1987, los trabajos fueron finalizados, pero no se alcanzó una conclusión determinante ni tuvieron un destino en los tribunales (Michelini, 1996: 160; Skaar, 2007: 54).

La otra fue la "Comisión Investigadora sobre la situación de las personas desaparecidas y los hechos que la motivaron". La comisión formaba parte de la estructura de la Cámara Baja. Especialmente se investigaba: las desapariciones forzadas en Uruguay y las desapariciones de uruguayos en el exterior, principalmente en Argentina. En su informe final, presentado al Parlamento el 4 de noviembre de 1985, la Comisión concluyó:

La Comisión registró 174 desapariciones de personal en el período comprendido entre 1973 y 1978. De estos 118 eran hombres, 38 mujeres y ocho niños. 32 de estas desapariciones tuvieron lugar en Uruguay, y 127 casos de personas desaparecidas son de Argentina, tres en Chile y dos en Paraguay. Además, la comisión indicó que “... el poder judicial, de manera adecuada, técnica y constitucionalmente, podrá avanzar rápida y definitivamente en el esclarecimiento total de los hechos, acusaciones y determinando condenas a los culpables (Rico, 2008).

En la misma época, en la región, más específicamente en Argentina, la Comisión Nacional sobre la Desaparición de Personas (CONADEP) entregó el Informe Nunca Más, una investigación sobre las desapariciones forzadas durante el último régimen militar 1976-1983, en noviembre de 1984. El informe sirvió de base para los procesos penales y para juzgar a los miembros de la cúpula militar argentina. En diciembre de 1985, se dictó la sentencia condenando los miembros de las tres primeras juntas militares ${ }^{v}$ que gobernaron la Argentina, convirtiéndose en un evento sin precedentes para la JT a nivel internacional y un evento con un fuerte simbolismo que reverberó en todos los países de la región.

Así, en este complejo escenario, comenzaron a aparecer las primeras citaciones de la justicia penal uruguaya. El ambiente se tornó aún más tenso cuando el Comandante del Ejército, Hugo Medina, declaró que no se presentaría ante la justicia, abriendo la posibilidad de un desafío militar masivo. Para evitar una posible ruptura institucional, en medio de las negociaciones, la solución para que los militares y policias involucrados en violaciones de derechos humanos no fueran acusados fue la sanción de la Ley 15.848, de diciembre de 1986, con el título de Ley de Caducidad de la Pretensión Punitiva del Estado. La ley, de nombre evasivo, trataba de la amnistía general que obligaba a archivar todas las denuncias en curso. ${ }^{\mathrm{vi}}$ En ese momento, los tribunales estaban investigando 734 casos de violaciones de derechos humanos (Burt et al, 2015: 7).

La ley estableció el fin del derecho del Estado a procesar al personal policial y militar acusado de violaciones de derechos humanos entre 1973 y 1985. Sin embargo, hay particularidades de la ley que requieren aclaración. El artículo 3 de la ley obliga al Poder Judicial a presentar al Poder Ejecutivo todas las denuncias presentadas para que éste decida si son adecuadas o no a la nueva ley. ${ }^{\text {vii }}$ Además, el artículo 4 obliga al Estado, encabezado por el Poder Ejecutivo, a investigar las denuncias sobre el destino de los desaparecidos durante la última dictadura militar. viii

La nueva ley viola tanto la Constitución $\mathrm{Na}$ cional como los tratados internacionales en los que el Uruguay es parte. Cortó las atribuciones naturales del Poder Judicial, cambiando su independencia y poniéndolas bajo la competencia del Poder Ejecutivo. Como señala Errandonea (2008: 22), "el actor político aparece como el guardián de la transición, y los gobiernos del futuro tienen la posibilidad de calibrar la justicia retributiva de acuerdo a la conveniencia del momento". Con la ley, se desconoció los deberes de investigar, procesar y reparar como principio de igualdad ante la ley y las garantías del debido proceso (Prats, 2010; 230). La ley fortaleció al ejecutivo a expensas de debilitar a los tribunales (Skaar, 2007: 57).

A partir de los esfuerzos de los legisladores de la oposición (principalmente de la coalición de Izquierda Frente Amplia) y de los familiares de los detenidos desaparecidos, se presentó un recurso de inconstitucionalidad de la ley. El 2 de mayo de 1988, la Corte Suprema de Justicia ratificó la constitucionalidad de la Ley de Caducidad por 3 votos contra 2. En la Sentencia 184/88, la Corte Suprema estableció la extinción punitiva del Estado, además de considerar que se trata de mecanismos válidos de extinción y son competencia del Poder Legislativo. Dos de los cinco magistrados del Tribunal expresaron su opinión en disidencia. ${ }^{\text {ix }} \mathrm{Su}$ argumento central era que la ley no respetaba la separación de poderes. Y que la Constitución no autoriza la delegación de poderes originales. Los argumentos utilizados por los disidentes se volvieron a plantear en otras ocasiones. Así, desde la ley de "amnistía", y la confirmación de la constitucionalidad de la misma por la justicia, se ha construi- 
do la impunidad en el retorno democrático. El Poder Judicial no tardó en adaptarse a las condiciones del modelo de impunidad.

La impunidad ha sido combatida por la sociedad, en particular por los movimientos sociales, las organizaciones de derechos humanos y, en menor medida, los partidos políticos quiénes han seguido buscando otros medios con horizonte en la verdad y la justicia. Como parte de las iniciativas alternativas, y como característica única en la región, la lucha continuó a través de un referendo (artículo 79 de la Constitución de la República Oriental del Uruguay), con el objetivo de convocar a un referendo popular para anular la ley. ${ }^{\mathrm{xi}}$

Después de dos años de movilización popular, a partir de la campaña del Voto Verde, ${ }^{\text {xii }}$ se alcanzó el número de firmas necesario para celebrar el referén-

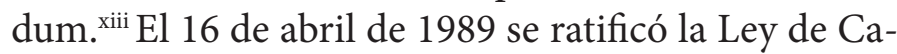
ducidad, con el apoyo del $57 \%$ de los votantes contra el 43\% que quería impugnar la ley (Prats, 2010, 231). El resultado sería crucial para silenciar temporalmente la discusión en Uruguay. La principal consecuencia, como indica Errandonea (2008: 24) fue: "La ley de impunidad fue violada por una triple legitimación: la del poder político, la del Poder Judicial y -ahora- la del ciudadano". Como señala Skaar (2007: 57):

(...) el único caso en la historia del mundo en el que el pueblo de un país democrático ha ratificado una ley que concede la impunidad militar a través de un referéndum". Este evento tuvo tres efectos importantes. En primer lugar, los militares tienen ahora una garantía formal de que no serán procesados. En segundo lugar, la sociedad civil estaba totalmente desilusionada. En tercer lugar, la ley convirtió formalmente el enjuiciamiento militar en una cuestión política y no jurídica.

Sin embargo, a pesar de las adversidades, según Michelini (1996: 163):

(...) el plebiscito permitió que los sectores más afectados por las violaciones de la dictadura militar tomaran un camino cívico para expresar su desacuerdo con impunidad legal. Asimismo, significó una campaña para difundir la dictadura y las violaciones de los derechos humanos cometidas en todo el país, y fortaleció el sistema democrático al aceptar a todos, sin excepción, los resultados de las urnas.

Así, la agenda política consolidó un horizonte de impunidad y serían necesarias estrategias nuevas e innovadoras en el futuro.

En diciembre de 1989 se presentó el Informe "Uruguay Nunca Más" del Servicio de Paz y Justicia (SERPAJ). ${ }^{\text {iv }}$ El objetivo era reunir información sobre las violaciones de los derechos humanos (no sólo las desapariciones) en el período 1972-1985. El informe, basado en un esfuerzo de la sociedad civil, sin apoyo y con financiamiento de organizaciones internacionales, trató de reemplazar la ausencia de documentación oficial. En él se identificaron 171 desapariciones forzadas, además de la aplicación sistemática de la tortura y las detenciones políticas. A pesar de la importancia y el esfuerzo realizado, el informe quedo en las sombras del referéndum. Aun así, su importancia quedará demostrada en el futuro al ser el informe utilizado como evidencia en numerosos procesos legales (Centro de Estudios Legales y Sociales, 2013: 102).

A lo largo de todo este proceso, parecería que el precio por la paz que pagó la sociedad es la falta de justicia. Y de esta forma se invertía la teoría de que la democracia se consolida a través de la justicia, aunque para los sectores que negociaron la transición, la justicia fue un problema para la reconstrucción democrática del país (Galain Palermo, 2014: 160). En definitiva, una mirada hacia el futuro sin elaborar el pasado. Pero ese pasado estará presente por el resto del futuro.

\section{La continuidad de la impunidad: Lacalle en la presidencia (1990-1995)}

La llegada a la presidencia de Luis Alberto Lacalle, del Partido Nacional, no cambiaría el escenario de impunidad. Pero en este proceso, las noticias vinieron de afuera de Uruguay. En octubre de 1991, la Comisión Interamericana de Derechos Humanos (CIDH) de la Organización de los Estados Americanos (OEA), en su Resolución 35/91, declaró que la Ley de Caducidad violaba la Declaración Americana de los Derechos y Deberes del Hombre y en la Convención Americana sobre Derechos Humanos (Rico, 2008: 714). ${ }^{\mathrm{xv}}$

Dos años después de la ratificación de ésta vía referéndum, la misma Comisión Interamericana la analizó y estableció su posición en el Informe 29/92 de 1992. ${ }^{\text {vii }}$ De forma nítida, la Comisión estableció que (CIDH, 1992):

La Ley 15.848, de 22 de diciembre de 1986, es incompatible con el artículo XVIII (Ejecución de la Justicia) de la Declaración Americana de Derechos Humanos y Deberes del Hombre, y con los artículos 1,8 y 25 de la Convención Americana sobre Derechos Humanos.

Recomendó expresamente al Estado uruguayo: “... la adopción de las medidas necesarias para esclarecer los hechos e individualizar a los responsables de las violaciones de los derechos humanos ocurridas durante el período de facto". Esta posición de la Comisión fue tomada en consideración por los sectores que eran contrarios a la Ley de Expiración.

Una cuestión importante planteada por la Comisión se refiere a la legislación interna. En el considerando 30 se señala que: "La cuestión en estos casos no es la de la legitimidad interna de la legislación y

ISSN:2007-2120 
otras medidas adoptadas por el Gobierno para lograr los efectos que aquí se denuncian". La Comisión dejó claro que en el proceso de confirmación de la ley, los diferentes poderes del Estado uruguayo, no la hacen válida en el sistema internacional, por lo que esto no es excusa para violar la Convención.

En la misma línea, en mayo de 1993, el Comité de Derechos Humanos de las Naciones Unidas ${ }^{\mathrm{xvii}}$ señaló algunas observaciones (y preocupaciones) en el informe periódico del caso de Uruguay: “.... el Comité está particularmente preocupado porque, al aprobar la ley, el Estado Parte ha contribuido a crear un entorno de impunidad que podría socavar el orden democrático y dar lugar a otras graves violaciones de los derechos humanos".

Concretamente, el Comité recomendó al Estado Parte: "que prosiguiera sus esfuerzos para adaptar la legislación interna a las disposiciones del Pacto". Así, establece que no hay excusa para violar el Pacto sobre la base de la legislación interna. Pero también afirmó: "que se establezca una autoridad imparcial e independiente encargada de investigar la aplicación de las normas de derechos humanos y de recibir informes de violaciones" (UN, 1993). He aquí uno de los grandes desafíos de la JT uruguaya.

Por último, el Comité se ha posicionado de la misma manera que la Comisión en años anteriores y reiteró sus preocupaciones en 1998. ${ }^{\text {xviii }}$ El sistema internacional dejó claro el norte al que Uruguay debe adecuarse. En 1994, el Comité de Derechos Humanos de las Naciones Unidas, en su comunicado No. 322/1988, ${ }^{\text {xix }}$ lo reafirmó una vez más:

El Comité reafirma además su posición de que las amnistías por violaciones graves de los derechos humanos y la legislación, como la Ley 15.848, Ley de Caducidad de la Pretensión Punitiva del Estado, son incompatibles con las obligaciones que incumben al Estado parte en virtud del Pacto.

De esta forma, la lucha contra la impunidad tuvo la intervención de agentes internacionales, aunque no tuvieron efectividad inmediata, dejaron marcas (y argumentos) para el futuro.

\section{El regreso de Sanguinetti a la presidencia (1995- 2000)}

Las elecciones de 1994, ganadas por poco margen, colocarían a Sanguinetti por segunda vez en la presidencia. Sanguinetti no cambiaría el escenario con respecto a la impunidad, ni su posición con respecto a las violaciones de los derechos humanos cometidos en la dictadura. Este segundo período estuvo marcado por la retomada y reconstrucción de espacios de lucha en la sociedad, y mismo por un cambio en el escenario regional e internacional en la defensa y protección de los derechos humanos.

El 20 de mayo de 1996 se realizó la primera Marcha del Silencio por "Verdad, Memoria y Nunca Más" en la avenida 18 de julio de Montevideo, fecha que recordaba los 20 años del asesinato de Zelmar Michelini y Héctor Guitierre Ruiz en la ciudad de Buenos Aires. ${ }^{x x}$ La marcha fue convocada por organizaciones de familiares, de derechos humanos, sindicales y religiosas, así como por sectores políticos de izquierda. El éxito de la marcha la convirtió en un evento clave en la lucha contra la impunidad. Paralelamente, se consolidaron diferentes organizaciones y movimientos de derechos humanos, como Hijos de desaparaecidos uruguayos (HIJOS) en 1996, Memoria para armar en 1997, Crysol, Asociación de ex Pres@s Polí-tic@s de Uruguay en 2000, entre otras organizaciones (Lessa, 2014: 95).

Durante este período se hicieron algunas denuncias y reivindicaciones, pero deslegitimadas o rechazadas por la arquitectura institucional de la impunidad: el rechazo de la solicitud de Senador Raúl Michelini de una Comisión de la Verdad, el caso de la "Operación Zanahoria" iniciada en marzo de 1997 por el propio Michelini y que el magistrado Alberto Reyes ordenó su investigación, pero que terminó siendo bloqueado por la Ley de Caducidad y con el juez Reyes transferido a un juzgado de lo civil como sanción explícita por su "conducta", como una forma de "adestramiento del poder judicial".

Lo mismo ocurrió con las presentaciones de madres y familiares que solicitaron una investigación sobre las personas desaparecidas. Todos ellas bloqueadas y rechazadas por el muro de la ley de la impunidad, muriendo en la entrada de los tribunales (Lessa, 2014: 96; Roniger, 2012: 12; Michelini, 1996: 168). A pesar de la independencia del Poder Judicial, quedaba en la esfera del Ejecutivo los asuntos que trataban la revisión del pasado violento. Estas cuestiones se abordaron principalmente en la esfera política y no en el Poder Judicial. Pero la impunidad no se tradujo en la retirada de reclamaciones y demandas de la sociedad. Estas aumentarían, tanto a nivel local como internacional.

En el escenario internacional, en marzo de 1995, la confesión del capitán argentino Adolfo Scilingo ${ }^{\mathrm{xxi}}$ fue particularmente especial debido a los informes sobre los "Vuelos de la Muerte"xxii y su correlación con la ubicación de los cadáveres en la costa argentina. Esta confesión reverberó en el país vecino, generando inquietud en Uruguay frente a la posibilidad de la existencia de uruguayos en estos vuelos, 
resurgiendo el pasado en la conciencia pública (Allier, 2006: 88; Roniger, 2012: 11).

En los días siguientes, el Comandante en Jefe del Ejército Argentino, Martín Balza, hizo un mea culpa en la televisión, reconociendo el uso de métodos ilegales, incluida la supresión de la vida, para obtener información, en la última dictadura argentina. $\mathrm{Al}$ mismo tiempo, familiares argentinos y organizaciones de derechos humanos (con el apoyo de organizaciones locales en cada país de destino) presentaron denuncias en varios países para acceder a su jurisdicción bajo el principio legal de la nacionalidad de la víctima. xxiii Estos acontecimientos dejaron marcas y precedentes, movilizando a la sociedad. Así, las transformaciones en el ámbito internacional estaban influyendo en los procesos domésticos. En el mismo año se promulgó la Ley 16.724, que incorpora la Convención Interamericana sobre Desaparición Forzada de la OEA.

A fines de 1999, el poeta Juan Gelman, en su lucha internacional, hizo público el reclamo que había hecho al presidente de Uruguay, Julio M. Sanguinetti. Gelman tenía pruebas de que su nuera, que había desaparecido en la Argentina y estaba embarazada en el momento de su detención, había sido trasladada al Uruguay y que su hijo había sido secuestrado por los autores. Al principio, Sanguinetti era receptivo, pero luego paralizó las investigaciones. Sanguinetti declaró: "En Uruguay no desapareció ningún niño" (Sanguinetti, 2000), volviendo al discurso de negación (Demasi, 2016: 3). ${ }^{\text {xiv }}$ Las quejas y presiones para investigar la denuncia de Gelman provenían de diferentes puntos cardinales. Y se convertiría en un asunto urgente para ser abordado por el próximo presidente.

Al mismo tiempo, la detención del dictador chileno Pinochet ${ }^{\mathrm{xxv}}$ marcó la apertura de posibilidades (y especialmente de esperanza) en la efectivad de la lucha contra la impunidad. La visibilidad del caso Pinochet redobló los incentivos a las demandas y la lucha de los familiares y las organizaciones de derechos humanos. Como indica Sikkink (2013), en relación con los juicios contra la humanidad, estos ayudan a disuadir más allá de las fronteras, y es probable que los procesos tengan mayor poder de disuasión en el país donde se llevan a cabo, existe también la posibilidad de encontrar un mayor grado de prevención o discusión general, afectando a los países vecinos.

Durante este período, el escenario internacional fue alimentando y fortaleciendo los reclamos internos. Pero la internalización de las noticias internacionales en los tribunales locales tuvo oídos sordos. Al igual que en Argentina, en Uruguay la discusión fue recuperando espacio en la sociedad. Un espacio luchado y construido por la militancia y el esfuerzo de familiares, movimientos y organizaciones de derechos humanos y no por las ausentes políticas públicas del gobierno en el poder.

\section{Un paso tímido y un punto de inflexión: Batlle en la presidencia (2000-2005)}

Jorge Batlle finalmente ganó en la segunda vuelta (después de sellar un acuerdo programático con el Partido Nacional) con más del 52\% de los votos, en contra de la fórmula de la Frente Amplia - Encuentro Progresista, encabezado por Tabaré Vázquez. ${ }^{x x v i} \mathrm{La}$ llegada de Jorge Batlle al ejecutivo uruguayo cambiaría la posición frente a las demandas de los sectores de derechos humanos, un cambio tímido, pero un punto de inflexión, un cambio que surgió de las demandas y clamores por la verdad y la justicia, tanto a nivel nacional como internacional. En su primer discurso Battle, prometió todos los esfuerzos para "devolver la paz a todos los uruguayos". La cuestión de las violaciones de los derechos humanos en la última dictadura estaba en la agenda y mismo, se puso en uso el artículo 4 de la Ley de Caducidad como conducto para ordenar investigaciones que esclarecieran el destino de las personas desaparecidas.

Desde el momento en que Batlle asumió la presidencia, el asunto Gelman gritaba por una resolución basada en las fuertes demandas de los más diversos sectores nacionales e internacionales desde el fin del gobierno de Sanguinetti. El 31 de marzo, el presidente, en una audiencia especial, anunció que la nieta del poeta estaba viva y vivía en Montevideo. En este sentido, Batlle, por un lado, cerró la búsqueda de Gelman, pero por el otro, reabrió un tema más amplio, sobre las investigaciones de los desaparecidos, la información existente en el gobierno y la falsedad de las explicaciones oficiales, dando sin esperarlo, el espaldarazo a otros familiares en su búsqueda. Antes de confirmar el examen de ADN de la identidad de la nieta de Gelman, Batlle anunció la creación de una comisión para tratar específicamente la cuestión de los desaparecidos.

En este caso, el General Manuel Fernández fue arrestado como resultado de declaraciones que negaban cualquier aclaración sobre el paradero de los detenidos desaparecidos. En ese momento, Batlle recibió una representación de la asociación de familias en una audiencia oficial, convirtiéndose en el primer presidente en hacerlo. La presión aumentó. Se presentarían más casos, pero con un final similar a los anteriores: los límites políticos y legales de la Ley de Caducidad. Como fue el caso presentado por el caso de la desaparecida Elena Quinteiros en 1999. ${ }^{x x v i i}$ En el año 2000, la jueza Estela Jubette apoyó la petición desafiando la Ley de Caducidad a pesar de las presiones 
de diferentes sectores en contra de su actividad. Pero pagaría un precio alto, con la presión de varios sectores, en la misma línea que sufrieron otros jueces (Skaar, 2007: 60; Lessa, 2014: 98; Roniger, 2012: 12 14; Oliveira Alfaro, 2016, 10; Guianze, 2016:12).

La incorporación de la legislación en el derecho interno fue un paso importante hacia la reconstrucción de la arquitectura jurídica democrática y fue compatible con las obligaciones internacionales. La Ley 17.347 de la Convención sobre la Imprescriptibilidad de los Crímenes de Guerra y de los Crímenes contra la Humanidad fue aprobada en junio de 2001, por su parte la Ley 17.510 del Estatuto de Roma de la Corte Penal Internacional fue aprobada en junio de 2002.

En junio de 2001, la Plenaria Intersindical de Trabajadores - Convención Nacional de Trabajadores PIT-CNT denunció al ex Ministro de Relaciones Exteriores y diputado del Partido Colorado Juan Carlos Blanco (y a otros tres altos funcionarios) involucrados en el caso de Elena Quinteiros. En 2002, la magistrada María del Rosario Berro acusó a Blanco de participar en el secuestro y desaparición de Elena Quinteros. El principal argumento para evitar la Ley de Caducidad fue que Blanco era un civil no amparado por la ley, por lo que ordenó las investigaciones. (Skaar, 2007; 62). En marzo de 2002, el coronel José Nino Gavazzo fue condenado por violaciones de derechos humanos.

El evento más importante de este mandato fue el establecimiento de la Comisión de Paz COMIPAZ), instalada en la Resolución 858/000 de la Presidencia de la República el 9 de agosto de 2000. La Comisión estaba integrada por importantes personalidades que representaban a los partidos políticos (Colorado, Nacional y Frente Amplia), la Iglesia Católica, la central obrera y las organizaciones familiares. ${ }^{\text {xxix }}$ La Comisión fue el primer paso real por parte del Poder Ejecutivo para asumir alguna responsabilidad en su deber de investigar y conocer la verdad sobre las violaciones de derechos humanos durante el pasado reciente (Prats, 2010: 232).

Las tareas de la Comisión fueron: "recibir, analizar, clasificar y recoger información sobre las desapariciones forzadas ocurridas durante el gobierno cívico-militar". Además de "recibir documentos y testimonios... manteniendo estrictas reservas sobre sus acciones". Según el presidente Batlle, el objetivo de la Comisión era intentar "consolidar la pacificación nacional y sellar para siempre la paz entre los uruguayos". Pero según la Comisión, el objetivo inmediato era "averiguar la situación y el destino de los detenidos desaparecidos durante el régimen de facto" (COMIPAZ, 2003: 6-8).
La COMIPAZ funcionó dentro de la órbita del Poder Ejecutivo, tenía un mandato restringido, poderes inquisitivos limitados y, por supuesto, carecía de atribuciones judiciales porque no era un órgano judicial (Allier, 2006: 90; Galain Palermo, 2009: 399; Demasi, 2016: 3). Como indica Errandonea (2008: 42), tanto las tareas como los objetivos de la Comisión se refieren más a la recepción que a la investigación, una actitud más recolectora y clasificadora que dé busca activamente. Ni la identificación de los responsables formaba parte de la labor de la Comisión ni la remisión de información a la justicia.

El Informe Final fue entregado al presidente Batlle el 10 de abril de 2003, como se indica en el Informe Final:xxx la Comisión recibió 38 denuncias específicas de presuntas desapariciones en Uruguay, 32 uruguayos y 6 argentinos. Veintiséis de las denuncias uruguayas fueron confirmadas, una no confirmada, otra no pudo ser confirmada o descartada, y otras cuatro fueron descartadas. Fueron 13 denuncias confirmadas de individuos que murieron en Argentina. También indicó la muerte de 41 personas más y confirmó parcialmente otras 72 denuncias. Confirmaron dos denuncias de desaparecidos uruguayos en Paraguay, uno en Bolivia, y destacaron dos denuncias de desapariciones, uno en Brasil y otro en Colombia (Prats, 2010: 233; COMIPAZ, 2003: 16-24). Entre otras conclusiones de la comisión.

Dentro del proceso de la JT uruguaya, las recomendaciones finales del Informe dejaron algunas orientaciones importantes que permanecieron en debate a lo largo de la trayectoria de lucha. Según la Comisión, es necesario promover: "una iniciativa legal tendiente a crear la figura específica y propia de la ausencia por desaparición forzada" (COMIPAZ, 2003: 30). Añadiendo que:

Se revean y actualicen nuestras normas legales vigentes, de forma de contemplar delitos (como, por ejemplo, tortura, delitos contra la humanidad, genocidio, desaparición forzada, etc.) ... con la finalidad de evitar y reprimir los excesos y los desvíos en que pueda incurrir el propio Estado y sus agentes (COMIPAZ, 2003: 33).

Además, proporcionó orientación sobre las reparaciones e indemnizaciones que debían pagarse a los familiares de las víctimas. Sin embargo, las recomendaciones no se aplicaron. El Ejecutivo editó la Resolución 448/003, aceptando las conclusiones del Informe Final, declarándolas como versión oficial en abril de 2003. ${ }^{\text {xxi }}$ Pero era una verdad parcial, por las características del informe y las limitadas atribuciones de la Comisión. La Resolución Ejecutiva 449/003 esta bleció la creación de una Secretaría de Seguimiento de la Comisión de Paz para continuar con el trabajo 
pendiente. Pero la Secretaría sólo tendría un trabajo residual (Mota, 2016: 5).

El impacto de la labor de la Comisión no ha sido de los mejores. Tanto el sector de los derechos humanos como el militar, por diferentes razones, criticaron los resultados modestos e insuficientes, y de impacto parcial (Prats, 2010: 233; Allier, 2006: 92), mientras que otros señalaron la existencia de información y datos falsos (Mota, 2016: 5 Errandonea (2008: 45). A pesar de las críticas al trabajo de la Comisión, el debate estaba dispuesto nuevamente entre la sociedad y en los medios de comunicación. Como señala Demasi (2016: 3):

A pesar de sus limitaciones, el Informe incorporaba una novedad radical: reconocía oficialmente la existencia de casos de desaparición forzada en Uruguay que mostraban la aplicación de una política sistemática, y que el Estado era responsable de estas desapariciones; por tanto, correspondía que proporcionara una respuesta a las demandas de los familiares y de las organizaciones sociales.

Lejos de sellar definitivamente la paz entre todos los uruguayos, como deseaba el presidente Batlle, el informe volvió a colocar el tema en la agenda política. Las recomendaciones de la Comisión no fueron implementadas y la Ley de Caducidad continuó aplicándose. Tal vez un ejemplo simbólico del estado del Informe Final de COMIPAZ es que no fue considerado por la justicia penal (Galain Palermo, 2014: 166).

En 2004, se publicó el Informe $A$ todos ellos. Informe de Madres y Familiares de Uruguayos Detenidos, otro esfuerzo de la sociedad civil sobre la suerte de los detenidos desaparecidos.

\section{La impunidad acorralada: Tabaré Vázquez (2005 a 2010)}

Con las elecciones presidenciales de octubre de 2004, llegarían las novedades. En primer lugar, la Frente Amplia, un partido de coalición de izquierda, ganaría las elecciones sin necesidad de una segunda vuelta y con un apoyo expresivo (Lanzaro, 2012). ${ }^{\text {xxxii }}$ Con su llegada, la Frente Amplia tuvo mayoría en el Parlamento (Garcé, 2010: 500). Terminaría de esta forma 120 años de gobiernos ininterrumpidos del Partido Colorado y del Partido Nacional, y 175 años de hegemonía de gobiernos Colorados, Nacionalistas o dictaduras.

La llegada de Vásquez a la presidencia significó un cambio de dirección en el proceso de JT. Desde una trayectoria de negación, obstrucción y ocultación, el presidente abrió las esperanzas para un nuevo momento de lucha por la verdad y la justicia.
En su discurso inaugural ante el parlamento, y como tema prioritario, Vásquez destacó: "Entre las primeras acciones del gobierno está la constitución de un grupo de trabajo por la verdad y la justicia, cuyo compromiso esencial será la investigación de los crímenes cometidos en el marco de la dictadura" (Vázquez, 2005: 2).

En su administración, se pusieron en marcha algunas demandas demoradas sobre las violaciones de los derechos humanos en la dictadura: se activaron los procesos judiciales contra los perpetradores, se inició la arqueología en los cuarteles y se abrieron los archivos oficiales (Demasi, 2016: 2). Pero estas activaciones no estaban exentas de problemas y limitaciones, importantes limitaciones. La trayectoria sería en zigzag.

A diferencia de los mandatos anteriores, la justicia volverá a ser un espacio de disputa con resultados inciertos, y no simplemente una manifestación de rechazo. Con base en estrategias legales centradas en aspectos poco claros de la Ley de Caducidad, el Ejecutivo decidió que algunos casos específicos (delitos económicos, delitos cometidos por civiles, policías o militares de alto rango de la dictadura, delitos cometidos en el extranjero y apropiación ilegal de menores) estaban fuera de la ley (Prats, 2010: 233; Lessa, 2014: 103; Alves Nogueira y Paiva Carvalho, 2016: 168). Sin embargo, cuanto mayor era la actividad en la esfera judicial, mayores eran los desafíos y las limitaciones.

De forma inédita, Vásquez, a partir de la $R e$ solución 755/005, encomendó a los Comandantes en Jefe del Ejército, de la Armada y de la Fuerza Aérea para llevar a cabo una investigación exhaustiva sobre el destino de los detenidos desaparecidos y el papel desempeñado por cada sector militar, además de realizar búsquedas de los restos (Prats, 2010: 234). De los cinco informes presentados por los distintos sectores de las Fuerzas Armadas entre agosto y noviembre de 2005, se admitió la detención, ejecución y entierro clandestino, y se reconoció el intercambio con sectores militares en Argentina. También indicaron información sobre el destino de las personas desaparecidas y los lugares de entierro; y reconocieron públicamente el uso de vuelos clandestinos de Buenos Aires a Montevideo (Rico, 2015; Rico, 2008: 75-105; Lessa, 2014: 106).

En la misma resolución, el presidente encargó a la Universidad de la República (Grupo de Investigación en Arqueología Forense de la Universidad de la República - GIAF, con el apoyo del equipo argentino de Antropología Forense) que colaborara en la búsqueda del destino de los restos y encomendó que se llevara a cabo una investigación a fondo para recoger las evidencias de las violaciones de derechos humanos 
durante la dictadura. El informe final se presentó en mayo de 2007 con el nombre de Investigación histórica de detenidos desaparecidos. xxxiii

Como parte del proceso de reconstrucción y reparación, y en consideración al Informe Final de la COMIPAZ, en septiembre de 2005, se promulgó la Ley 17.894 que creó la categoría legal de "ausente por desaparición forzada”. En la misma línea y con la intención de conciliar la legislación interna con los tratados internacionales, se aprobó, en septiembre de 2006, la Ley 18.026, que modifica el código penal, incorporando los crímenes de lesa humanidad y la desaparición forzada. Se promulgaron otras leyes, alterando gradualmente la arquitectura jurídica existente hasta entonces. xxxiv

Vázquez, en noviembre de 2005, envió al Parlamento una ley interpretativa de la Ley de Caducidad para "reforzar por medios legales lo que ya se está haciendo dentro de la ley". Con fuerte críticas de los diversos sectores (militares, oposición y algunos de derechos humanos), finalmente el gobierno decidió no promover la iniciativa. En el campo de la reparación, los pasos no serían significativos.

La búsqueda de los restos tuvo resultados modestos, encontrando dos desaparecidos, tratándose de los primeros hallazgos de estas características en Uruguay. Pero el evento conmovió a la opinión pública, al desmentir el relato defendido de que no existían desaparecidos, colaborando para consolidar el nuevo norte de la política de derechos humanos del nuevo gobierno (Roniger, 2012:16; Demasi, 2016:3).

Desde la llegada de Vázquez, las causas judiciales avanzaron en aproximadamente 25 casos de violaciones de derechos humanos, que involucran a aproximadamente 60 víctimas. Varios militares uruguayos fueron arrestados y puestos en prisión, tanto por sentencia como por prisión preventiva (Errandonea, 2008: 37).

En noviembre de 2006, una amplia coalición de grupos de la sociedad civil lanzó una iniciativa popular de reforma constitucional para anular la Ley de Caducidad. ${ }^{\mathrm{xxx}}$ Inicialmente, no todos los sectores apoyaron la iniciativa. La Frente Amplia no apoyó la campaña por el plebiscito y el candidato presidencial del partido (José Pepe Mujica) sólo expresó su apoyo al final de la campaña presidencial. Después de un intenso trabajo de las diferentes organizaciones y de la sociedad civil, lograron más de 337.000 firmas, superando las requeridas (Burt et al, 2015: 14; Roniger, 2012: 17; Rico, et al 2014: 186). El plebiscito estaba programado para el 25 de octubre de 2009, coincidiendo con las elecciones nacionales.
Una semana antes del plebiscito y de las elecciones nacionales, el 19 de octubre de 2009, la Corte Suprema de Justicia, en el caso de Nibia Sabalsagaray, también conocida como Sentencia $365^{x x x v i}$ estableció que la Ley de Caducidad era inconstitucional para el caso concreto. Se trato de un giro jurisprudencial en consideración a la sentencia dictada por la SCJ sobre la ley en 1988. En un evento importante, el 22 de ese mismo mes, la SCJ condenó al ex dictador Gregorio Álvarez a 25 años de prisión.

El 25 de octubre de 2009, el plebiscito fue apoyado por el $48 \%$ de los votantes a favor del fin de la ley, no logrando los votos necesarios. Hay varias lecturas sobre este resultado. Algunos argumentan que fue eclipsado por las elecciones nacionales y que el Partido Frente Amplia estuvo más preocupado por asegurar la victoria de Pepe Mujica y lograr una mayoría legislativa. Algunos indican que se trató de una desconfianza jurídica en la institucionalización de un instrumento de anulación de leyes. Otros señalan que fue simplemente la ratificación de la ley por la mayoría. Sectores también señalan las características de los procedimientos de votación. .xxvii

Para otros, la falta de información, publicidad y desinformación obstaculizó la iniciativa. (Burt et al, 2015: 15; Prats, 2010: 235; Rico et al, 2014). En palabras de Sikkin (2015) "hay ciertas decisiones que no pueden dejarse a las mayorías. Creo que es peligroso permitir que las mayorías determinen qué derechos vamos a conceder o no a las minorías. Y las víctimas de las violaciones de los derechos humanos son "minorías". En la misma línea, Zaffaroni (2015) indica: "El riesgo con Uruguay es que si te vas a un mayoritarismo hace entonces un derecho plebiscitario y una democracia plebiscitaria. Eso sí, deja de ser directamente democracia porque la primera mayoría hace pelota a las minorias".

A diferencia del referéndum de 1989, en el que la desesperanza y el silencio temporal se apoderaron de la sociedad, el plebiscito generó un mayor movimiento y revitalización de los sectores de derechos humanos y de la sociedad civil, incluido el surgimiento de nuevas organizaciones.

\section{José "Pepe" Mujica al poder (2010 a 2015)}

En la segunda vuelta, José Pepe Mujica ganó las elecciones con más del 52 por ciento de los votos en contra el candidato del Partido Nacional Alberto Lacalle. La Frente Amplia logró mantener la mayoría absoluta en el parlamento (Garcé, 2010: 518). La llegada de Mujica a la presidencia tuvo un enorme simbolismo en el proceso de revisión del violento pasado. ${ }^{\text {xxxviii }}$ Pero este simbolismo tenía que ser traducido y materializado 
en lo real. El proceso de la JT se encontraba en una nueva fase y en el ámbito judicial se multiplicaron las disputas políticas y legales, pero aún no se había consolidado el nuevo rumbo. Y fueron las organizaciones de la sociedad civil y de derechos humanos, desde abajo hacia arriba, las que lucharon e impulsaron la innovación.

El movimiento en los tribunales tuvo algunas condenas notorias: en febrero de 2010 los dos ex dictadores Juan María Bordaberry y Gregorio Álvarez fueron procesados y sentenciados. El primero fue condenado a 30 años de prisión por liderar el golpe de 1973, además de una serie de asesinatos; el segundo fue condenado a 25 años de prisión por 37 asesinatos calificados. En abril de 2010, Juan Carlos Blanco fue condenado a 20 años de prisión por el asesinato de Elena Quinteros. En junio de 2011, Bordaberry y Blanco también serán condenados por ordenar y coordinar los asesinatos de los opositores Zelmar Michelini y Héctor Gutiérrez Ruiz, y de los ex guerrilleros Rosario Barredo y Willliam Whitelaw. En mayo de 2013, hubo la primera condena de un oficial militar en actividad, el general Miguel Dalmao, por el asesinato de Nibia Salbasagaray (Burt y al, 2015: 13; Lessa, 2016: 6; Skaar, 2011: 146).

A finales de 2010, la Frente Amplia impulsó un proyecto de ley para derogar las disposiciones de la Ley de Caducidad y así permitir que las causas avanzasen antes de la inminente decisión de la Corte Interamericana (por el Caso Gelman). Después de la aprobación en la Cámara de Diputados, éstas no pasarían por el Senado Nacional. En los debates, el referéndum, el plebiscito y la legitimidad de la voluntad popular fueron argumentos que aunaron apoyos. Incluyendo a tres senadores del Frente Amplia que no se opusieron al proyecto. Finalmente, y después de varios meses de debate, el proyecto de ley fue aprobado en el Senado Nacional en abril de 2011, tras el fallo de la CIDH (Burt et al, 2015: 16). Con la devolución del proyecto de ley a la Cámara de Diputados para su aprobación final, la polarización se multiplicó. Incluso la interferencia del presidente Mujica fue parte del proceso.

Finalmente, el proyecto cayó en un callejón sin salida. La Alta Comisionada de las Naciones Unidas para los Derechos Humanos, Navi Pillay, criticó en el Consejo de Derechos Humanos de la ONU el rechazo del proyecto interpretativo de la Ley de Caducidad, indicando que su continuidad: "blinda a los autores de crímenes internacionales cometidos durante la dictadura militar, y ha sido declarada inconstitucional por la Corte Suprema uruguaya" (Pillay, 2011). De esta manera se abrió una nueva instancia de debates e iniciativas, con la Ley de Caducidad firme, y el desconcierto y desaliento de las organizaciones de derechos humanos (Rico et al, 2014: 124).

Después de la presentación ante la $\mathrm{CIDH}$, ante la imposibilidad de obtener justicia en Uruguay, el caso Gelman fue remitido a la Corte Interamericana de Derechos Humanos. El 24 de febrero de 2011, la Corte publicó su sentencia:

Dada su manifiesta incompatibilidad con la Convención Americana, las disposiciones de la Ley de Caducidad que impiden la investigación y sanción de graves violaciones de derechos humanos carecen de efectos jurídicos y, en consecuencia, no pueden seguir representando un obstáculo para la investigación de los hechos del presente caso y la identificación y el castigo de los responsables, ni pueden tener igual o similar impacto respecto de otros casos de graves violaciones de derechos humanos consagrados en la Convención Americana que puedan haber ocurrido en el Uruguay (CIDH, 2011: 68).

Así, la Corte Interamericana se pronunció sobre la Ley de Caducidad alineada con los casos Barrios Altos vs. Perú (2001), La Cantuta vs. Perú (2006), Almonacid Arellano vs. Chile (2006) y Gomes Lund vs. Brasil (2010).

La sentencia también dividió opiniones, con respecto a la legitimidad de la Ley de Caducidad otorgada por el referéndum de 1989 y el plebiscito de 2009, cuando la Corte estableció: “... la protección de los derechos humanos constituye un límite infranqueable a la regla de mayorías, es decir, a la esfera de lo "susceptible de ser decidido" por parte de las mayorías en instancias democráticas” (CIDH, 2011: 69). xxxix La sentencia creó un nuevo piso para debatir el pasado violento y las necesidades actuales de la democracia. Desde el inicio, las distintas organizaciones de derechos humanos tuvieron un doble propósito: por un lado, asegurar el cumplimiento de las obligaciones impuestas por la $\mathrm{CIDH}$; por otro lado, consolidar el esfuerzo de unidad permanente de aquellos actores sociales que deberían tener un papel fundamental en el proceso de justicia (Oliveira Alfaro, 2016: 10). La sentencia en el caso Gelman no fue una sentencia contra Uruguay, sino a su favor.

Como parte del proceso de cumplimiento de la sentencia de la CIDH, el 30 de junio de 2011, Mujica aprobó la Resolución 323/2011, que revocó administrativamente las resoluciones adoptadas por los gobiernos anteriores (1985-2005) que amparadas por la Ley de Caducidad frenaban denuncias de violaciones de derechos humanos cometidas bajo la dictadura. Así, el sistema de justicia se encargaría de completar la tarea de desarchivar las causas, investigar los hechos y sancionar a los responsables (Oliveira Alfaro, 2016: 
26). De esta manera, se eliminaron los obstáculos para el enjuiciamiento penal en 88 casos que se habían presentado entre 1986 y 2005 y que fueron remitidos a los tribunales para su investigación. Pero, la Ley de Caducidad podía bloquear nuevos casos llevados ante la justicia (Burt et al, 2015: 17). En este escenario, surgieron nuevos problemas, no (sólo) de naturaleza jurídica, sino de incapacidad material y la falta de herramientas institucionales y administrativas para asegurar la eficacia del proceso de justicia.

El tema de la prescripción era un tema recurrente: como las violaciones de los derechos humanos cometidas bajo la dictadura eran juzgadas como delitos comunes, podían ser objeto de prescripción, y la fecha límite era el 1 de noviembre de $2011 .^{\text {xl }}$ De esta manera, se acabaría con la posibilidad de presentar nuevas denuncias e iniciar futuros procesos por crímenes que no se conocen como crímenes de lesa humanidad. Pero rápidamente, el Ejecutivo elaboró un proyecto de ley para restablecer la pretensión punitiva del Estado y declarar los crímenes como de lesa humanidad.

El 27 de octubre de 2011, la Cámara de Representantes aprobó la Ley 18.831, que restituye la pretensión punitiva del Estado por los crímenes cometidos durante el período dictatorial. En su artículo 2, estableció que no se computará ningún plazo, ni procesal, ni de prescripción ni de caducidad. En su tercer artículo, declaró que: "los delitos a que refieren los artículos anteriores, son crímenes de lesa humanidad de conformidad con los tratados internacionales de los que la República es parte”.

Entre 2011 y 2012 llegó a los tribunales un número importante de casos. Según las estadísticas del Observatorio Luz Ibarburu (OLI) cada año se inician aproximadamente 80 casos (OLI, 2016b). En marzo de 2012, en representación del Estado uruguayo y en cumplimiento de lo dispuesto en la sentencia de la Corte Interamericana de Derechos Humanos de 24 de febrero de 2011, el presidente Mujica declaró:

El Estado uruguayo reconoce que en el pasado se cometieron en el país acciones violatorias de los derechos humanos. (...). se llevó adelante una política sistemática de represión. (...) Y el desarrollo de esa Doctrina de la Seguridad Nacional, el Estado Uruguayo integró el llamado Plan Cóndor.

Y admitió la responsabilidad por la violación de las garantías judiciales por la falta de investigación, enjuiciamiento y sanción efectiva de los autores en detrimento de Juan y Macarena Gelman, "como consecuencia de la interpretación y aplicación por parte del Estado de la Ley de Caducidad de la Pretensión Punitiva del Estado" (Mujica, 2012). Durante este período, se realizaron más actividades en cumplimiento de las obligaciones impuestas por la CIDH. ${ }^{\text {xli }}$

En el mismo mes, inspirado en otros observatorios de la región, xlii el PIT-CNT creó el OLI de las Causas Judiciales y de Políticas Públicas en materia de derechos humanos, con el fin de contribuir a sistematizar la información, mejorar y asegurar el pleno acceso a la justicia. La iniciativa recibió el apoyo y las contribuciones de diversos sectores y organizaciones del Uruguay y de la región. ${ }^{x l i i i} S u$ actividad es fundamental para el desarrollo de la JT. ${ }^{\text {xliv }}$ Como señala Olivera Alfaro (2016: 26), existían:

(...) causas que no habían sido desarchivadas a partir de la resolución del Poder Ejecutivo que lo había dispuesto. Comprobamos nuevamente que la investigación, el aporte de información, testimonio y el impulso procesal continuaban dependiendo casi exclusivamente de los denunciantes y las organizaciones de la sociedad civil.

Otra demostración de obstrucciones y obstáculos en la dimensión de la justicia, y una sustitución de roles, una transferencia de responsabilidad del Estado a la sociedad civil. Pero la presión terminaría por crear el "equipo auxiliar de justicia para los crímenes de terrorismos en agosto de 2013". El equipo había colaborado directamente con los operadores jurídicos del Poder Judicial en casos relacionados con la investigación de delitos cometidos en el marco del terrorismo de Estado. ${ }^{\text {lv }}$

Una medida que fue ampliamente criticada en febrero de 2013, fue la que la Corte Suprema de Justicia, mediante la Resolución 70/2013, dispuso el cambio de la Magistrada Mariana Mota de un tribunal penal a un tribunal civil. Al igual que Reyes y otros, ${ }^{\mathrm{xl}-}$ vi la transferencia de Mota fue una sanción para una magistrada que tenía en sus manos aproximadamente 50 casos de violaciones de derechos humanos. Las críticas se convirtieron en movilizaciones, comunicados y protestas de los diferentes sectores de la defensa de los derechos humanos, la sociedad civil, políticos y las organizaciones de magistrados y otras entidades regionales (Rico et al, 2014: 137-152). xlvii

En este tumultuoso proceso, la Corte Suprema de Justicia volvería a estar en las noticias: días después de la transferencia de Mota, la SCJ declaró inconstitucionales los artículos 2 y 3 de la reciente

Ley $18.831 .^{\text {xlviii }}$ Los principales argumentos de la sentencia indicaron que los artículos 2 y 3 fueron declarados inconstitucionales, puesto que, vulneran ostensivamente el principio de retroactividad de la ley penal (Rico et al, 2014: 155). 
En la misma línea, la Suprema Corte de Justicia dictó otras sentencias. ${ }^{\text {xlix }}$ Las reacciones vinieron de los más diversos sectores.

El fallo sorprendió a los observadores derechos humanos por su descarado desconocimiento de derecho internacional de los derechos humanos y por su desprecio de las obligaciones internacionales ratificadas voluntariamente por parte de Uruguay". Esto está completamente desfasado con respecto a la jurisprudencia internacional y constituye un gran revés a los esfuerzos de Uruguay para llegar a una solución con respecto a las violaciones de los derechos humanos del pasado reciente (Burt y Lessa 2013).

La Alta Comisionada de las Naciones Unidas expresó su preocupación por el fallo de la Corte Suprema, que abrió el camino para el cierre de las investigaciones en curso sobre violaciones de derechos humanos, violando el derecho de las víctimas a la verdad, la justicia y la reparación (Pillay, 2013). En el mismo sentido, la Comisión Interamericana de Derechos Humanos se pronunció sobre la sentencia: "es una muestra de que no existe seguridad jurídica alguna en Uruguay sobre la eliminación de los efectos de la Ley de Caducidad de la Pretensión Punitiva del Estado como mecanismo de impunidad de los graves crímenes cometidos durante la dictadura" (CIDH-OEA, 2013). Según Pablo Greiff (2013), Relator Especial de la ONU sobre su visita a Uruguay en octubre de 2013, declaró:

En Uruguay se procesó penalmente a un ex presidente electo y un ex presidente de facto, a un ex ministro, y algunos miembros de alto rango de las Fuerzas Armadas. Hay un número importante de causas abiertas, alrededor de 140. De momento, sin embargo, nada parece amenazar más las posibilidades de progreso en el área de la justicia que decisiones recientes de la Suprema Corte de Justicia.

Galain Palermo (2014: 175) indica que la sentencia demuestra que la nueva Ley 18.831 no parece haber sido un acierto legislativo, sino un nuevo y apresurado antídoto a la cuestionada Ley de Caducidad para resolver un aspecto puntual del proceso de JT.

En marzo de 2013, la Corte Interamericana de Derechos Humanos publicó su supervisión del cumplimiento de la sentencia del Caso Gelman. Estableciendo claramente que:

La obligación del Estado de dar pronto cumplimiento a las decisiones de la Corte es parte intrínseca de su obligación de cumplir de buena fe con la Convención Americana y vincula a todos sus poderes y órganos, incluidos sus jueces y órganos vinculados a la administración de justicia, por lo cual no puede invocar disposiciones del derecho constitucional $\mathrm{u}$ otros aspectos del derecho interno para justificar una falta de cumplimiento de la sentencia (CIDH, 2013: 31).
Por lo tanto, los argumentos sobre la irretroactividad del derecho penal y los límites de no considerar los crímenes como de lesa humanidad no están de acuerdo con la Convención.

A partir del retroceso establecido por la Corte Suprema del Uruguay las consecuencias comenzarían a florecer. Parte de ellas tuvo su manifestación en las actitudes que los magistrados tendrían en relación con los casos reabiertos. En abril de 2013, la magistrada Fanny Canessa determinaría la clausura y el archivamiento por prescripción del caso Sosa Bustos. Pocos días después, la magistrada Beatriz Larrieu deslegitimó la solicitud de clausura por prescripción. En la misma sintonía se posicionó el juez Juan Carlos Fernández Lecchini siguiendo la Sentencia 152/2013, y la magistrada Julia Elena Staricco Campodonico, en el caso de denuncia de 28 mujeres por violencia sexual. Entre las diferentes concepciones y opiniones jurídicas que existían en disputa en los tribunales a finales de abril de 2013, el general Miguel Dalmao y el coronel José Chialanza fueron condenados a 28 años de prisión por "homicidio muy especialmente agravado", como en el caso Nibia Sabalsagaray.

Como señala Olivera Alfaro (2016: 12), con el traslado del magistrado Mota, la inconstitucionalidad de dos artículos de la Ley 18.831, y de algunas posturas de algunos fiscales y jueces que sustentan la prescripción de los delitos, marcó una etapa que se juntaba la impunidad fáctica, por un lado, y a la amenaza legal, por otro. El sistema de justicia se convirtió en una arena de disputas políticas y legales, pero no hubo una solución real a las violaciones de los derechos humanos en la dictadura.

\section{Los laberintos de la justicia: segunda presidencia de Tabaré Vázquez (2015-2020)}

Tabaré Vásquez, del Frente Amplio, ganó las elecciones del 30 de noviembre de 2014 con más del 53 por ciento de los votos en la segunda vuelta contra Luis Lacalle Pou, del Partido Nacional, asumiendo la presidencia por segunda vez. De esta manera, la Frente Amplia logró obtener su tercer mandato consecutivo de gobierno, extendiendo la era progresista. El ciclo electoral de 2014 permitió a la Frente Amplia mantener su mayoría parlamentaria, aunque sea menor que en los otros dos períodos anteriores de gobierno ( $\mathrm{Lu}-$ jan y Lopez Burian, 2016).

En un brochazo de actualidad, el último reporte actualizado por el OLI (2019), encontró que: existen 305 denuncias penales por los delitos de la dictadura en los tribunales uruguayos. De estas, el $50 \%$, es decir 151 causas, se encuentran en la etapa de pre-sumario; el 13\%, 41 causas, han sido acumuladas 
a otras; mientras que el $30 \%$, es decir 94 denuncias, han sido archivadas; solamente 4 se encuentran en etapa de sumario. Existe entonces un total de 170 causas activas. Se ha dictado sentencia de condena únicamente en 13 causas, que corresponde al 5\% del total. Se destaca la existencia de casos judiciales en el exterior, principalmente en Argentina y una en Italia, y son fundamentales en este proceso (Rico, 2015: 20). La sociedad civil, siempre movilizada, sigue esperando resultados.

En cuanto a los archivos, a pesar de algunos avances, ${ }^{1}$ los distintos sectores de la Fuerza Aérea (FFAA) siguen ocultando archivos y no aportan información sobre los detenidos desaparecidos, lo que se ha convertido en un fuerte límite al derecho a la memoria y a la verdad. Los países de la región están aún muy lejos de haber consolidado la forma en que se trata a los archivos represivos en la experiencia internacional (Caetano, 2011: 29). Todavía hay una falta de reglamentar la ley de acceso a la información y la entrega de documentos se ve complicada por obstáculos legales (Guianze, 2016: 6; Alves Nogueira y Paiva Carvalho, 2016: 171; Chargoñia, 2011: 174).

Entre las novedades institucionales, a partir del Decreto 131/2015, en mayo de 2015 se creó el Grupo de Trabajo Verdad y Justicia, integrado por reconocidas figuras en la lucha contra la impunidad. lii La Secretaría de Derechos Humanos en el pasado reciente es su soporte funcional y administrativo. El propósito esencial del grupo es investigar los crímenes de lesa humanidad cometidos por los agentes del Estado o por quienes actuaron apoyados por el Estado, dentro o fuera de sus fronteras, en el marco de la acción ilegítima del estado y del terrorismo de Estado. Pero con objetivos muy amplios, no tiene atribuciones específicas para el cumplimiento de sus compromisos, tiene poca coordinación con otros actores y no ha presentado los avances realizados ni ha informado sobre sus actividades hasta la fecha (Mota, 2016: 6; Guianze, 2016: 5).
Finalmente, el gobierno resolvió desactivar el Grupo de Trabajo por Verdad y Justicia, en agosto de 2019. El Poder Ejecutivo remitió al Parlamento un proyecto de ley para que las tareas desarrolladas por ese grupo pasen a ser realizadas por la Institución Nacional de Derechos Humanos (INDDHH), fortaleciendo su independencia. ${ }^{\text {liii }}$

Otra innovación fue la creación de la Unidad especializada en Derechos Humanos por la Resolución 002/2015 de septiembre de 2015. La unidad está dirigida por el Fiscal Adjunto de la Corte. ${ }^{\text {liv }}$ Su función es asesorar, analizar, coordinar, capacitar y difundir la información que sea necesaria para facilitar la actuación eficiente y eficaz de los representantes de la Fiscalía General de la Nación en los procesos judiciales relacionados con las graves violaciones de los derechos humanos cometidas durante la dictadura (1973-1985). Según el OLI (2016a: 193), la unidad es: "subutilizada, por desconocimiento de su papel y de las posibilidades que puede ofrecer como ayuda a la justicia”.

En junio de 2016, el Senado aprobó el proyecto de ley para adelantar la entrada en vigor del nuevo código de procedimiento penal. De esta manera, el nuevo código comenzó a regir a partir de julio de 2017, por primera vez, éste dió participación a las víctimas de delitos. En este sentido, parte del debate fue transferir a los fiscales la competencia para dirigir las investigaciones penales hoy conducidas por los jueces (Alves Nogueira y Paiva Carvalho, 2016: 172). Pero es la actuación de la sociedad civil hasta el día de hoy la que sigue asumiendo el papel que correspondería al Estado. La sociedad civil sigue siendo el principal auxiliar de la justicia (OLI, 2016: 191).

Sobre el transcurso de la segunda presidencia de Tabaré Vázquez, muchos eventos que influencian el área específica de JT fueron desarrollándose, como fue describiéndose (Del Rio, 2019). Especialmente, en el 2019, varios eventos fueron (y son) relevantes, por su simbolismo y por los desafíos.

\section{Cuadro 2}

Lemas de las Marchas del Silencio celebradas cada 20 de mayo

- 2015. Basta de impunidad • 2017. Impunidad del ya: verdad y justicia

- 2016. Ellos en nosotros. Contra la impunidad de ayer y hoy. Verdad y Justicia
- 2018. Impunidad: responsabilidad del Estado ayer y hoy
Estado Ayer y hoy

- 2019. ¡Que nos digan dónde están! Contra la impunidad de ayer y hoyli 
En primer lugar, la importancia e influencia del contexto regional, de una fuerte onda neoliberal autoritaria, con ADN color verde oliva. Tal vez, todo se sintetice en la figura controvertida del Presidente Brasileño, Jair Bolsonaro, explicito defensor de la tortura, de la dictadura y de la violencia como forma de resolución de conflictos. En este sentido, los desafíos domésticos (y de la Frente Amplia en especial) se multiplican, lidiando contra los discursos de la oposición (similares a los de los países vecinos) que reclaman políticas de seguridad más duras, participación y colaboración de los militares en la seguridad interna, y propuestas de horizonte de olvido, en palabras del ex comandante del ejército, Manini Rios: hay que dejar de hablar de "cosas que ocurrieron hace muchísimo tiempo". vii

En segundo lugar, las relaciones cívico-militares en Uruguay. El presidente Tabaré Vázquez ordenó la detención por 30 días del comandante del Ejército Guido Manini Ríos por "repetidas faltas disciplinarias" en septiembre de 2018. Manini Ríos fue sancionado según indica la Constitución: "que no permite a los militares ejercer ningún tipo de actividad política en el cargo"." "viii La sanción surgió como resultado de las reiteradas manifestaciones públicas de Manini Ríos expresando su posición en contra de la reforma del fondo de pensiones militar. Es un hecho sin precedentes que un presidente civil ordene el arresto de un comandante militar del Ejército de la Nación. Un acontecimiento único si pensamos el momento actual del Cono Sur. Pero lejos de complacer a los sectores conservadores y militares, el malestar que era grande en estos sectores, ahora alentados por el contexto regional se multiplicaron. Recordemos que Manini Ríos fue invitado a la toma de protesta de Jair Bolsonaro.

Mientras más días le transcurrían al 2019, un año electoral, la tensión en las relaciones cívico-militares en Uruguay se profundizaron, el 12 de marzo, cuando el presidente Tabaré Vázquez destituyó al mismo comandante, después de que el militar criticara una vez más la reforma de las pensiones militares y anunciara su intención de entrar en política. ${ }^{\text {lix }} \mathrm{A}$ los pocos días, el nuevo partido político Cabildo Abierto nombró a Manini Ríos como candidato presidencial, lo que aumentó la tensión doméstica. En una conferencia de prensa, el partido señaló su norte: "La importancia de recuperar los valores éticos, morales, culturales, educativos, sociales, de honestidad y de seguridad que se han perdido lenta pero seguramente a lo largo de los años". Y añadieron: "la familia es la base de la sociedad, el formador inicial de los valores humanos". Ix Un discurso muy conocido en Brasil.

A principios de abril de este año, en un nuevo conflicto, Tabaré Vázquez destituyó al primer nivel del
Ministerio de Defensa, al nuevo comandante en jefe del Ejército y a dos generales que formaron un tribunal honorario que juzgó la conducta de los soldados condenados por delitos contra los derechos humanos durante la dictadura (1973-1985). De esta manera, las tensiones en las relaciones cívico-militares han multiplicado los problemas, poniendo sobre la mesa el debate sobre la memoria, la verdad y la justicia, un proceso que en Uruguay tiene avances y retrocesos, pero sobre todo una parálisis (y barrera) en los tribunales de justicia por los crímenes de la dictadura.

El 8 de abril asumió el cargo de comandante en jefe del ejército de Claudio Feola. En declaraciones extremadamente conflictivas, el nuevo comandante Claudio Feola dijo: "No repudiaré los acontecimientos pasados porque no sé si están confirmados o no"lxi A pesar de la retractación posterior de Feola, el debate sobre la memoria, la verdad y la justicia se ha consolidado en la mesa de discusión.No faltaron las repercusiones, y el 11 de abril, en una multitudinaria manifestación en el centro de Montevideo, bajo el lema por la democracia y contra la impunidad, se escuchó a la sociedad uruguaya. ${ }^{\text {lxii }}$

En tercer lugar, como vimos, en este contexto regional de inestabilidad institucional y de democracia contra las cuerdas, con las relaciones cívico militares alteradas y con el debate sobre memoria, verdad y justicia en la mesa de debate nacional, la campaña electoral de las presidenciales para octubre del 2019, tuvo presentes todas estas cuestiones. Recientemente, la Frente Amplia recupero su liderazgo electoral, aunque con probable segunda vuelta. La novedad, es que el fortalecimiento de los partidos tradicionales y la consolidación del partido Cabildo Abierto como cuarto colocado. Este último, alcanzaría un 15\% del electorado, dando voz a sectores que desean eliminar el proceso de JT en Uruguay. En este proceso, las agendas de las políticas de seguridad y la participación de los militares en la seguridad interior, así como de los vecinos, son parte central de los desafíos del presente. Y con ellos, la disputa por la memoria, la verdad y la justicia. Los movimientos sociales y de derechos humanos están movilizando las calles.

En cuarto lugar, el 8 de julio de este año, el Tribunal de Apelaciones de Roma, en una sentencia histórica, condenó a cadena perpetua a un total de 24 militares y autoridades de Bolivia, Chile, Perú y Uruguay por la desaparición y muerte de unos 20 italianos en relación con el plan Cóndor. ${ }^{\text {xiii }}$ Entre los condenados, 14 eran de Uruguay. En un manifiesto, ${ }^{\text {lxiv }}$ Crysol (Asociación de ex presos políticos de Uruguay) afirmó que la decisión de la Corte de Roma: "es el espejo en el que el Poder Judicial (de Uruguay) debe ser visto 
para superar la ineficiencia que escandaliza a la sociedad". La Comisión Interamericana de Derechos Humanos, en un comunicado oficial, destacó que observa con gran preocupación que, a pesar de los esfuerzos realizados por el Estado, persisten interpretaciones judiciales en procesos penales que niegan la imprescriptibilidad de las graves violaciones de los derechos humanos durante el período de la dictadura cívico-militar.

Estas interpretaciones dan lugar a la impunidad de los autores de crímenes de lesa humanidad y niegan la justicia y la reparación a las víctimas. En este sentido, la Comisión recuerda al Estado su obligación de dar pleno cumplimiento a la sentencia de la Corte Interamericana de Derechos Humanos en el caso Gelman vs. Uruguay, en la que se establece que:

(...) las disposiciones de amnistía, la prescripción y el establecimiento de la exclusión de responsabilidad tienen por objeto impedir la investigación y sanción de los responsables de violaciones graves de los derechos humanos, tales como la tortura, las ejecuciones sumarias, extralegales o arbitrarias y las desapariciones forzadas, todas las cuales están prohibidas por violar derechos inderogables reconocidos por el derecho internacional de los derechos humanos. ${ }^{\mathrm{lxv}}$

Así, la Comisión solicitó al Estado, especialmente al Poder Judicial, que cumpliera con su deber de aplicar el control de convencionalidad en el marco de su obligación de respetar y garantizar los derechos humanos de conformidad con las decisiones de la Corte Interamericana y de la Convención Americana. Así, las novedades que provienen del ámbito internacional conmueven el ámbito doméstico, reforzando el debate sobre la memoria verdad y justicia en Uruguay.

Finalmente, como quinto evento, a fines de agosto de 2019, fueron hallados restos humanos en el ex Batallón 13 y semanas más tarde se confirmó que pertenecían a Bleier, militante del Partido Comunista del Uruguay, que había sido secuestrado mientras caminaba por la calle el 29 de octubre de 1975. En todo el periodo democrático, solo cinco restos habían sido hallados. ${ }^{\text {lxvi }}$ De esta forma, este evento, reforzó nuevamente la discusión de la memoria, verdad y justicia en Uruguay. A mediados de octubre, una multitud despidió los restos de Eduardo Bleier en la antesala del Paraninfo de la Universidad de la República, con presencia de Tabaré Vázquez, Felipe Michelini, y otras personalidades. ${ }^{\text {lxvii }}$

\section{Consideraciones finales: un horizonte incierto}

Los países de la región están revisando su pasado violento reciente. La JT en la mayoría de los países de América del Sur tiene hoy en día dos características: está cada vez más judicializada y cada vez más internacionalizada. Pero son la calidad y las características de esta judicialización y la capacidad institucional para interiorizar las novedades internacionales las que son fundamentales para entender cada caso de estudio. Cada país revisa su pasado violento y traumático a su forma y velocidad, según sus estructuras, instituciones y movimientos sociales. Uruguay ha demostrado que es un caso único de cómo enfrentó (y está enfrentando) su pasado violento, y ha tomado su propio camino, a diferencia de los otros países del Cono Sur.

En el proceso de JT en Uruguay, hay dos grandes momentos. El primero entre 1985-2005 y el segundo entre 2005-2016. El primero, con los gobiernos del Partido Colorado y el Partido Nacional en el poder, la impunidad era una política de Estado. En las tres primeras administraciones, los presidentes no sólo estuvieron recelosos de enfrentarse a los legados de las violaciones de los derechos humanos, sino que también se esforzaban por desalentarlos y obstruirlos. La Ley de Caducidad funcionó como una amnistía en manos del Poder Ejecutivo, de manera discrecional y arbitraria (Galain Palermo, 2014: 165).

Según Skaar (2007: 63), en relación con las razones de los jueces para no poder avanzar: en primer lugar, el legado de la Ley de Caducidad; en segundo lugar, la continua dependencia del Poder Judicial en el Poder Ejecutivo. En el camino, el escenario internacional trajo innovaciones y directrices claras contra la impunidad, pero la receptividad fue mínima. En el período de transición de los partidos en el poder, en el gobierno de Batlle, el último del Partido Colorado, se dieron los primeros pasos, incluso con resultados mínimos. La Comisión, a pesar de los resultados mínimos, colocó el tema de las violaciones de los derechos humanos en la dictadura en la agenda política y social.

El segundo momento, con los gobiernos de la Frente Amplia, a partir de 2005, la receptividad fue mayor, pero no se tradujo en gobiernos que lideraron políticas de memoria. Eran receptivos, pero no eran líderes; permitieron avances significativos en comparación con la absoluta falta de actividades de los momentos precedentes. A pesar de la legislación publicada, la Resolución 323/2011 de Mujica y la promulgación de la Ley 18.831, la Ley de Caducidad continúo siendo un límite, un muro con grietas provocadas por innovaciones legales y la actividad de algunos fiscales y jueces audaces.

El caso Gelman abrió esperanzas, pero mostró poca (tradición y formación) de la internalización del derecho internacional en los tribunales uruguayos en materia de violaciones de derechos humanos en la 
dictadura, a pesar de la ratificación de tratados y convenciones. La esfera judicial se ha convertido en una arena de disputas legales y políticas. A pesar de los esfuerzos, de todas las causas, actualmente se ha dictado sentencia de condena únicamente en 13 causas, que corresponde al 5\% del total (OLI, 2019). Persisten los obstáculos y los jueces siguen observando a las élites políticas en los casos de violaciones de derechos humanos en la dictadura (Skaar, 2013: 4). Los gobiernos de esta última época consideraron que correspondía al Poder Judicial atender las demandas de verdad y justicia. Un punto importante es que cuando existe la voluntad del Poder Ejecutivo, se puede avanzar más en el área de justicia (Skaar, 2011: 153). Al igual que el reconocimiento oficial de la responsabilidad del Estado por las violaciones de los derechos humanos en la dictadura. Hay innovaciones institucionales que están en proceso de adaptación y mejora de sus funciones. Pero todavía tienen pocos resultados y se enfrentan a muchos retos endógenos y exógenos.

En Uruguay no se han establecido tribunales especiales para el tema, ni se han establecido tribunales de competencia exclusivos para manejar estos procesos, ni se ha capacitado a los magistrados (y operadores de justicia) para que consideren las particularidades de los casos con características nacionales excepcionales. Es importante destacar la falta de conocimiento (o de voluntad) por parte de los jueces para aplicar el derecho internacional de los derechos humanos (Lessa, 2016: 7).

Existen deficiencias, tanto materiales como en las herramientas institucionales y administrativas para la eficacia del proceso de justicia (OLI, 2016: 191). La lentitud con la que se tramitan los casos es otro obstáculo en este proceso (Equipo Jurídico del OLI, 2015). Además, existe la estrategia común de parte de las defensas de los militares de ir dilatando los juicios y demorar las resoluciones. Dados los recursos actuales del que dispone el sistema de justicia, sin la participación y contribución activa de las víctimas, denunciantes, familiares y organizaciones de derechos humanos, poco se puede avanzar (CELS, 2013: 105; Prats, 2010: 236 Chargoñia, 2011: 171).

Además, los delitos económicos cometidos por agentes del Estado durante la dictadura fueron excluidos de todas las investigaciones. Tampoco se ha intentado determinar la responsabilidad civil, limitando el campo de investigación al personal militar individualizado en cada caso. No se han denunciado los numerosos actos de tortura que ha sido el mecanismo sistemático para el tratamiento de los detenidos y reclusos. (Mota, 2016: 3-5; Chargoñia, 2011: 170).
En 2011, un grupo de 28 mujeres, presas políticas durante la última dictadura cívico-militar (19731985), presentó ante la justicia una denuncia penal por las violaciones y abusos sexuales a los que fueron sometidas por agentes del Estado en diferentes centros de reclusión. ${ }^{\text {lxviii }}$ La denuncia quedó estancada varios años. Recién en 2016 fue procesado un ex militar, Asencio Lucero, de los muchos denunciados, pero sólo por el delito de privación ilegal de la libertad. ${ }^{\text {lxix }}$ A principios de 2019, la Fiscalía Especializada en Crímenes de Lesa Humanidad solicitó el procesamiento con prisión de tres militares jubilados y un expolicía. Se trata de un tema que intenta salir de la invisibilidad a base de la fuerza de las mujeres que realizaron la denuncia. Se remarca especialmente la ausencia de avances en esta área específica.

En todo momento se disputó para que las denuncias relativas a los crímenes cometidos durante el terrorismo de Estado tramiten como denuncias de delitos comunes. Esta calificación permite la aplicación de la Ley de Prescripción que determina la clausura de los casos. En este escenario, es fácil beneficiarse del arresto domiciliario, que está expresamente excluido para quienes han sido procesados por crímenes de lesa humanidad, una cualidad que no ha sido atribuida. Sumando las dificultades existentes en relación con los archivos de la dictadura, cuanto más tiempo pase, más ardua será la tarea de su tratamiento (Guianze, 2016: 5; Caetano, 2011: 29).

Actualmente, la falta de una política de Estado homogénea, cohesionada y coordinada, que involucre a los tres poderes del Estado, es uno de los factores de resultados erráticos (Guianze, 2016: 6). Uruguay avanzó de forma intermitente y tumultuosa tras la elaboración de mecanismos legales y jurídicos, como soluciones políticas y culturales al legado de violaciones de derechos humanos, en la búsqueda de una normativa democrática en la búsqueda de la verdad y la igualdad ante la ley. (Roniger, 2012: 18).

La actual postura de la Suprema Corte de Justicia coloca al Uruguay en una situación de oposición radical a la jurisprudencia mayoritaria, no sólo en la región, sino también a nivel internacional. Como indica Sikkin (2015), si un país realmente quiere lograr resultados y convertirse en una democracia sólida, debe realizar juicios. En este sentido, existió en esta trayectoria de JT una continuidad que fue cambió gradualmente, tímidamente, pero no existió ruptura. El alma de la Ley de Caducidad sigue en vigor después de más de 30 años de vida, a pesar de existir una Ley interpretativa de la Ley de Caducidad, esta ha sido considerada inconstitucional por la Suprema Corte de Justicia en el 2013. De esta forma, como señala Alicia 
Castro (2018): "el obstáculo actual es la discusión sobre la prescripción de los delitos amparados por aquella ley y la constitucionalidad de los arts. 2 y 3 de la Ley No 18.831”. Además, como indica el OLI (2019):

(...) podemos afirmar que la sentencia Gelman no fue cumplida por el Estado uruguayo, pues luego de ella no se incrementó la persecución penal por causas seguidas por violaciones a los derechos humanos durante el Terrorismo de Estado. No se investigó ni juzgó como ordenaba esa sentencia internacional y, por el contrario, el proceso que había impulsado la sociedad civil tiempo atrás, se paralizó.

La trayectoria de la JT parece haber entrado en una nueva fase, con una pierna en la arena de la dimensión de la justicia. El escenario es complejo y el proceso todavía está en construcción. Como vimos, actualmente, las novedades externas como domésticas, problematizan y colocan nuevos obstáculos y desafíos en el horizonte.

No se debe intentar un mero conocimiento del pasado, sino trabajar con el pasado. La elaboración del pasado está en construcción y aún no está cerrada. (Galain Palermo, 2009). Pero la desconexión entre el pasado violento reciente y el presente, que no investiga lo ocurrido, no garantiza la no repetición, que es uno de los objetivos esenciales de la JT.

Todavía es muy necesario seguir investigando el pasado en el ámbito del debate público (Allier, 2006: 92). Los familiares y las organizaciones de derechos humanos han sido (y son) fundamentales en este sentido. $Y$ en un escenario regional de retrocesos en derechos sociales y derechos humanos, de gobiernos conservadores y violencia institucionalizada, nacen nuevos desafíos y obstáculos en el horizonte. El proceso está en marcha y tiene un largo camino por recorrer. Como se indica en el Informe Uruguay Nunca Más (1989: 4) sobre el pasado violento reciente: “... rescatar esa historia es aprender una lección, sacar conclusiones para mirar con los ojos sin vergüenza hacia el futuro".

\section{Referencias}

Allier, Eugenia. (2006). Exploración/Exploration the Peace Commission: A Consensus on the Recent Past in Uruguay? European Review of Latin American and Caribbean Studies, 81, October.

Alves Nogueira, Amanda Raquel, Paiva Carvalho, Claudia. (2016). Uruguay - Panorama da justiça de transição em 2015. En C. Paiva; J. Nogueira; M. Guerra, Justicia de transición en América Latina: panorama 2015. Brasília: Ministério da Justiça, Comissão de Anistia, Rede Latino-Americana de Justiça de Transição (RLAJT).
Burt, Jo-Marie, Lessa, Francesca. (2013). Reciente sentencia de la Suprema Corte uru-guaya obstruye la búsqueda de verdad y justicia. Recuperado de http:// goo.gl/2H $2 \mathrm{ZzE}$

Burt, Jo-Marie; Fried, Gabriela y Lessa, Francesca. (2015). La sociedad civil y el resurgir de la lucha contra la impunidad en Uruguay (1986 2014). Alternativas, (5).

Caetano, Gerardo. (2015). 30 años de democracia: de la transición democrática a los gobiernos de la izquierda (1985-2015). En SERPAJ-Uruguay, Derechos Humanos en el Uruguay - Informe 2015. Uruguay: Servicio Paz y Justicia.

Caetano, Gerardo. (2011). Los archivos represivos en los procesos de justicia transicional: una cuestión de derechos. Perfiles Latinoamericanos (37), enero-junio.

Castro, Alicia. (2018). Derechos Humanos y Delitos De Lesa Humanidad: Un Análisis de la Jurisprudencia de la Suprema Corte de Justicia sobre Imprescriptibilidad de los Delitos de la Dictadura. Revista de Derecho Público, (54), diciembre.

Chargoñia, Pablo. (2011). Avances, retrocesos y desafíos en la lucha judicial contra la impunidad. En G. Fried y F. Lessa (Comp.), Luchas contra la impunidad Uruguay 1985-2011. Ediciones Trilce.

Comisión Interamericana de Derechos Humanos (CIDH OEA). (1992). Informe anual de la Comisión Interamericana de Derechos Humanos 1992 - 1993. Informe $\mathrm{N}^{\circ}$ 29/92. Casos: 10.029; 10.036; 10.145; $10.305 ; 10.372 ; 10.373 ; 10.374 ; y, 10.375$. Uruguay.

Comisión Interamericana de Derechos Humanos (CIDH-OEA). (2013). Comunicado de Prensa emitido al culminar el 147 Período de Sesiones.

Comisión para la Paz (COMIPAZ). (2003). Informe final. 10 de abril de 2003, Uruguay.

Corte Interamericana de Derechos Humanos - CIDH. (2011). Caso Gelman vs. Uruguay. Sentencia del a Corte Interamericana del 24 de febrero de 2011. (Fondo y Reparaciones) 
Del Río, Andrés. (2019). O pulso da memória. Seis meses da justiça transicional no Uruguai (2017). En C. Gallo (org.), No rastro das transições - perspectivas sobre memória, verdade e justiça no Cone Sul e no Sul da Europa. Pelotas: Editora da UFPel.

Del Río, Andrés. (2015). La dictadura argentina en el banquillo: la trayectoria de la justicia y punición a los responsables por los crímenes de lesa humanidad. Política, globalidad y ciudadanía, México, año 1, (1) Enero-junio.

Demasi, Carlos. (2016). La trasmisión del pasado traumático. Enseñanza de la dictadura y debate social en Uruguay. ILCEA. Recuperado de http://goo.gl/Tc$\mathrm{v} 4 \mathrm{pX}$

Centro de Estudios Legales y Sociales - CELS. (2013). Derechos Humanos en Argentina: Informe 2013. Buenos Aires: Siglo XXI editores.

Equipo Jurídico del Observatorio Luz Ibarburu EJOLI. (2015). Informe Anual 2015 del Observatorio Luz Ibarburu. Diciembre.

Errandonea, Jorge. (2008). Justicia Transicional en Uruguay. Revista IIDH Instituto Interamericano de Derechos Humanos, (47), enero-junio.

Filippini, Leonardo. (2012), Reconocimiento y justicia penal en el caso Gelman. Anuario de Derechos Humanos 2012, Facultad de Derecho. Universidad de Chile, (8).

Galain Palermo, Pablo. (2009). Uruguay. En K., Ambos; E. Malarino y G. Elsner (edi.), Justicia de transición. Informes de América Latina, Alemania, Italia y España. Uruguay. Fundación Konrad-Adenauer.

Galain Palermo, Pablo. (2014). El proceso de justicia de transición en Uruguay. En G. i Tosi (Org.), Justiça de transição: direito à justiça, à memória e à verdade. João Pessoa: Editora da UFPB.

Garcé, Adolfo. (2010). Uruguay 2009: De Tabaré Vázquez a José Mujica. Revista de Ciencia Política, 30 (2). Chile.

Gargarella, Roberto. (2011). 5 comentarios sobre la decisión de la Corte Interamericana en Gelman. En Seminario de Teoría Constitucional y Filosofía Politica. Recuperado de http://goo.gl/o8n0dL
Gargarella, Roberto. (2015). La democracia frente a los crímenes masivos: una reflexión a la luz del caso Gelman. LADI, Revista Latinoamericana de Derecho Internacional, (2). Recuperado de http://goo.gl/PvkrSJ

Greiff, Pablo Greiff. (2013). Relator especial de ONU presentó observaciones preliminares sobre su visita oficial a Uruguay. Prensa ONU. Recuperado de http:// goo.gl/ AxmHol

Guianze, Mirtha. (2016). La impunidad más allá de la Ley de Caducidad. Construcción de un marco jurídico nacional de derechos humanos vs. persistencia de la cultura de impunidad. ILCEA. Recuperado de http://goo.gl/ WrDQiC

International Center for Transitional Justice - ICTJ. (2010). What is Transitional Justice? Recuperado de http://bit.ly/2bbYIM9

Lanzaro, Jorge; y De Armas, Gustavo. (2012). Uruguay: clases medias y procesos electorales en una democracia de partidos. Instituto de Ciencia Política de la Facultad de Ciencias Sociales de la Universidad de la República. Montevideo, Uruguay.

Lessa, Francesca. (2019). Justicia más allá de las fronteras. Los crímenes transnacionales de Plan Cóndor. Latin American Centre: Universidad de Oxford.

Lessa, Francesca. (2014). Justicia o Impunidad. ¿Cuentas pendientes en el Uruguay pos-dictadura? Uruguay: Editorial Sudamericana.

Lessa, Francesca. (2016), ¿Justicia o impunidad? Cuentas pendientes a treinta años del retorno a la democracia. ILCEA. Recuperado de http://bit.ly/2bZogyZ

Lujan, Diego, Lopez Burian, Camilo. (2016). El tercer gobierno del frente amplio en Uruguay: supremacía electoral de la izquierda y perspectiva de reformas institucionales. POSTData 21, (1) Abril/2016-septiembre.

Michelini, Felipe. (1996). El largo camino de la verdad. Revista del IIDH, vol. 24.

Mota, Mariana (2016). Los difíciles caminos de la justicia en derechos humanos en Uruguay. ILCEA. Recuperado de http://bit.ly/2b3A-Z3P 
Mujica, José. (2012). Palabras del presidente Mujica en acto público del 21 de marzo. Secretaría de Comunicación. Presidencia de la República. Recuperado de http://tinyurl. com/h88krha

Observatorio Luz Ibarburu - OLI. (2019). Escrito de Amicus Curiae presentado ante la corte interamericana de derechos humanos por el observatorio luz Ibarburu en el caso Gelman vs. Uruguay. audiencia de supervisión de cumplimiento de sentencia. 5 de septiembre de 2019.

Observatorio Luz Ibarburu - OLI. (2016a). Ditadura e transição democrática no Uruguai. En C. Paiva; J. Nogueira; y M. Guerra, Justicia de transición en América Latina: panorama 2015. Brasília: Ministério da Justiça, Comissão de Anistia, Rede Latino-Americana de Justiça de Transição (RLAJT).

Observatorio Luz Ibarburu - OLI. (2016b). Reporte de estado de causas - agosto 2016. Recuperado de http://goo.gl/S3wQBR

Oliveira Alfaro, Raúl. (2016). Memoria, verdad y justicia en Uruguay: la gestión del pasado en un escenario de luces y sombras. ILCEA. Recuperado de http:// bit.ly/2bv87n7

Olsen, T., Payne, L. y Reiter, A. (2009). Equilibrando julgamentos e Anistias na América Latina: Perspectivas comparativa e Teórica. Revista Anistia Política e Justiça de Transição. Brasil (2), 152-175.

Pillay, Navia. (2011). El Consejo de Derechos Humanos inaugura su sesión número 17. Prensa Oficina Regional América del Sur. Naciones Unidas, Oficina del Alto Comisionado de derechos humanos. Recuperado de http://tinyurl.com/zhhesa3

Pillay, Navia. (2013). Alta comisionada de ONU para Derechos Humanos preocupada por decisión de la SCJ. El Observador 24 de febrero 2013. Recuperado de http://tinyurl. com/z3rx9oq

Prats, Martin. (2010). Uruguay. En Las víctimas y la justicia transicional. ¿Están cumpliendo los estados americanos con los estándares internacionales? Fundación para el Debido Proceso Legal. Washington, DC. DPLF

Presidencia. (2016), Policías y fiscales se capacitan para investigar crímenes de lesa humanidad. Comunicación. Recuperado de http://tinyurl.com/zh7hwyf
Rico, Álvaro (coord.). (2014). Cómo vota-ron los partidos en el plebiscito contra la caducidad en 2009 y la historia contra la impunidad 2006-2013. Montevideo: Ediciones Trilce.

Rico, Álvaro (coord.). (2008). Investigación histórica sobre la dictadura y el terrorismo de estado en el Uruguay (1973-1985). (Tomo IV). Uruguay: Universidad de la Republica.

Rico, Álvaro. (2009). Practicas estatales criminales en dictadura y relaciones sociales degradadas en Democracia, Uruguay. En D. Feierstein (Comp.), Terrorismo de estado y genocidio en América Latina. Buenos Aires: Prometeo Libros - PNUD.

Rico, Álvaro. (2015). Introducción. Actualización de la Investigación histórica sobre detenidos desaparecidos (1971-1982). Investigación histórica sobre asesinados politicos (1973-1985). Montevideo: Presidencia de la República, Secretaría de Derechos Humanos para el pasado reciente y la Universidad de la República.

Roniger, Luis. (2012), La sacralización del consenso nacional y las pugnas por la memoria histórica y la justicia en el Uruguay pos dictatorial. América Latina Hoy. España.

Sanguinetti, Julio María. (2000). En Uruguay no desapareció ningún niño. La Red Política 21. Recuperado en http://bit.ly/1j8QaH9

SERPAJ (1989), Uruguay Nunca Más Informe sobre la violación a los derechos humanos (1972-1985). Montevideo.

Sikkin, Kathryn. (2013). La cascada de la justicia. ¿Cómo los juicios de lesa humanidad están cambiando el mundo de la política? DF.: GEDISA.

Sikkin, Kathryn. (2015). Entrevista a Kathryn Sikkink. LADI, Revista Latinoamericana de Derecho Internacional, (2). Recuperado de http://bit.ly/2aZz41V

Skaar, Elin. (2007). Legal development and human rights in Uruguay: 1985-2002. Hu-man rights review.

Skaar, Elin. (2011). Impunidad versus responsabilidad jurídica: el rol de la Ley de Caducidad en Uruguay. En G. Fried y F. Lessa (comp.), Luchas contra la impunidad Uruguay 1985-2011. Montevideo: Ediciones Trilce. 
Skaar, Elin. (2013), Wavering Courts: From Impunity to accountability in Uruguay. Journal of Latin America Studies. 45 (03), August. Cambridge University Press.

U.N. Human Rights Committee. (1993). Comments on Uruguay, U.N. Doc.CCPR/C/79/Add.19 (1993).

U.N. Human Rights Committee. (1994). Rodríguez v. Uruguay, Communication No. 322/1988, U.N. Doc. CCPR/C/51/D/322/1988.

U.N. Human Rights Committee. (1998). Observações finais do Comité de Direitos Humanos, Uruguay. U.N. Doc. CCPR/C/79/Add.90.

UN Security Council. (2004). The rule of law and transitional justice in conflict and pos-t-conflict societies. Document: S/2004/616. Recuperado de http:// goo.gl/mGgATR

UN Security Council. (2011). The rule of law and transitional justice in conflict and pos-t-conflict societies. Document: S/2011/634. Recuperado de http:// goo.gl/mGgATR

Van Zyl, Paul. (2009). Promovendo a justiça transicional em sociedades pós-conflito. Revista Anistia Politica e Justiça de Transição, (1), 32-55. Brasil.

Vázquez, Tabaré. (2005). Discurso del presidente Tabaré Vázquez emitido en transmisión simultánea por radio y televisión. Comunicación. Recuperado de http://tinyurl.com/ju5c9vy

Zaffaroni, Eugenio Raúl, y Croxatto, Guido. (2015). Entrevista a Eugenio Raúl Zaffaroni y Guido Croxatto. LADI, Revista Latinoamericana de Derecho Internacional, (2). Recuperado de http://tinyurl.com/ zmya94b

${ }^{i}$ Lessa (2019): "El Plan u Operación Cóndor fue una red secreta de inteligencia y coordinación represiva instituida por las dictaduras de Argentina, Bolivia, Brasil, Chile, Paraguay y Uruguay a mediados de los años 1970 para secuestrar, torturar y asesinar a sus opositores políticos a lo largo y ancho de Sudamérica, convirtiendo dicha región en un área de terror e impunidad sin fronteras (ver mapa de los países de Cóndor, arriba). Cóndor tuvo su origen en cooperaciones informales y bilaterales entre las Fuerzas Armadas (FFAA) y de seguridad de Argentina, Paraguay, Chile y Uruguay desde por lo menos 1972. Su creación se formalizó posteriormente en una reunión en Santiago de Chile, entre el 25 de noviembre y el 1 de diciembre de 1975, organizada por la Dirección Nacional de Inteligencia (DINA), en la que participaron 50 oficiales de todos los países y presidida por el mismo
General Pinochet. Posteriormente, en 1976, Brasil se sumó formalmente al Cóndor; en 1978, Perú y Ecuador se incorporaron también".

ii Ley 15.783 de noviembre de 1985, sobre reposición de los destituidos. Se complementará con la Ley 17.449 de 2002.

iii Artículo $1^{\circ}$ de la Ley 15.737: "Decrétase la amnistía de todos los delitos políticos, comunes y militares conexos con éstos, cometidos a partir del $1^{\circ}$ de enero de 1962 . Respecto a los autores y coautores de delitos de homicidio intencional consumados, la amnistía sólo operará a los fines de habilitar la revisión de las sentencias en los términos previstos en el artículo $9^{\circ}$ de esta ley". iv En diciembre de 1985 se promulgó la Ley 15.798: Convención contra la Tortura y otros Tratos o Penas Crueles, Inhumanos o Degradantes.

v Fueron condenados: Jorge Rafael Videla, Roberto Eduardo Viola, Emilio Eduardo Massera, Armando Lambruschini y Orlando Ramón Agosti

${ }^{\text {vi }}$ Artículo $1^{\circ}$ de la Ley 15.848: “...ha caducado el ejercicio de la pretensión punitiva del Estado respecto de los delitos cometidos hasta el $1^{\circ}$ de marzo de 1985 por funcionarios militares y policiales, equiparados y asimilados por móviles políticos o en ocasión del cumplimiento de sus funciones y en ocasión de acciones ordenadas por los mandos que actuaron durante el período de facto".

vii Artículo $3^{\circ}$ de la Ley 15.848: "A los efectos previstos en los artículos anteriores, el Juez interviniente en las denuncias correspondientes, requerirá al Poder Ejecutivo que informe, dentro del plazo perentorio de treinta días de recibida la comunicación, si el hecho investigado lo considera comprendido o no en el artículo $1^{\circ}$ de la presente ley. Si el Poder Ejecutivo así lo comunicare, el Juez dispondrá la clausura y el archivo de los antecedentes. Si en cambio, no contestare o informa que no se halla comprendido dispondrá continuar la indagatoria. Desde la fecha de promulgación de esta ley hasta que el Juez reciba la comunicación del Poder Ejecutivo quedan suspendidas todas las diligencias presumariales en los procedimientos mencionados en el inciso primero de este artículo."

viii Artículo 4: "Sin perjuicio de lo dispuesto en los artículos precedentes el Juez de la causa remitirá al Poder Ejecutivo testimonios de las denuncias presentadas hasta la fecha de promulgación de la presente ley referentes a actuaciones relativas a personas presuntamente detenidas en operaciones militares o policiales y desaparecidas, así como de menores presuntamente secuestrados en similares condiciones. El Poder Ejecutivo dispondrá de inmediato las investigaciones destinadas al esclarecimiento de estos hechos. El Poder Ejecutivo dentro del plazo de ciento veinte días a contar de la comunicación judicial de la denuncia dará cuenta a los denunciantes del resultado de estas investigaciones y pondrá en su conocimiento la información recabada"

ix Addiego, Tommasino e Nicoliello por la mayoría, y en disidencia Balbela de Delgue e García Otero.

x Artículo 79: "El veinticinco por ciento del total de inscriptos habilitados para votar, podrá interponer, dentro del año de su promulgación, el recurso de referéndum contra las leyes y ejercer el derecho de iniciativa ante el Poder Legislativo. Estos institutos no son aplicables con respecto a las leyes que establezcan tributos. Tampoco caben en los casos en que la iniciativa sea privativa del Poder Ejecutivo. Ambos institutos serán reglamentados por ley, dictada por mayoría absoluta del total de componentes de cada Cámara."

xi En enero de 1987 se creó la Comisión Nacional Pro-referéndum para coordinar la campaña. El liderazgo estuvo representado por Elisa Dellepiane, Matilde Rodríguez Ruiz, María Esther Gatti, familiares de personas desaparecidas. Pero en la Comisión 
había representantes de las distintas organizaciones de familiares y sobrevivientes, de grupos de derechos humanos, de la Plenaria Intersectorial de Trabajadores - Convención Nacional de Trabajadores (PIT-CNT), de la Federación de Estudiantes (FEUU), de los actores del Frente Amplio, entre otros (BURT et al, 2015: 9).

xii El verde fue el color del papel para votar por la derogación de la ley, el amarillo fue el voto que apoyó la continuidad de la ley. xiiiEn Uruguay es necesario alcanzar el 25\% de las firmas de los ciudadanos registrados y habilitados para votar.

${ }^{\text {xiv }}$ La Comisión fue creada por SERPAJ en marzo de 1986.

${ }^{x v}$ Entre los años 1986 y 1989, la Comisión recibió 8 casos contra el Estado uruguayo, denunciando los efectos de la Ley de Caducidad.

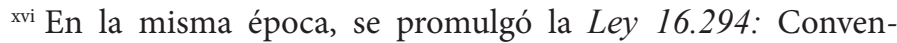
ción Interamericana para Prevenir y Sancionar la Tortura, 1108-1992. Otras leyes promulgadas de importancia fueron: Ley 16.519: Protocolo Adicional a la Convención Americana sobre Derechos Humanos (Protocolo de San Salvador), promulgada el 22-07-1994.

xviiComité de Derechos Humanos, Observaciones Uruguay: CCPR/C/79/Add.19, (05-05-1993).

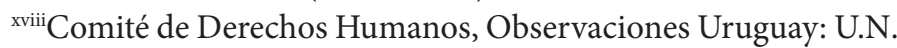
Doc. CCPR/C/79/Add.90 (08-04-1998).

xix Comité de Derechos Humanos, Comunicación No. 322/1988, U.N. Doc. CCPR/C/51/D/322/1988 (1994).

${ }^{x x}$ Las marchas de silencio se repetirán cada año, y cada una con consignaciones diferentes.

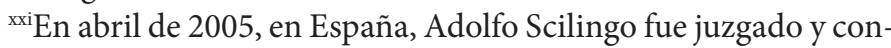
denado a 640 años de prisión. Recientemente, el Tribunal español aumentó la pena a 1.084 años.

xxii Vuelo de la muerte: los detenidos-desaparecidos que se encontraban en la Escuela Mecánica de la Marina (ESMA) y otros centros clandestinos de detención fueron drogados, atados y arrojados vivos desde aviones al Río de la Plata y al Océano Atlántico. xxiiiDesde 1996, España ha estado investigando lo sucedido en Argentina sobre la base del principio de la jurisdicción universal. La cara visible del caso era la del juez Baltazar Garzón. Magistrados de Francia (caso Astiz), Alemania (casos Kasemann y Zieschank) e Italia (caso Suarez Mason, y también utilizando el principio de la nacionalidad pasiva de la Operación Cóndor) (Del Rio, 2015: 62).

xxiv En el mismo sentido, en cuanto al secuestro de menores, está el caso de Simón Riquelo, quien nació en cautiverio después de que su madre Sara Méndez fuera arrestada en Buenos Aires en 1976. Después de ser liberada, comenzó a buscar al niño. Después de pasar por los diferentes tribunales uruguayos exigiendo una prueba de ADN, la Corte Suprema finalmente rechazó la solicitud en 1998.

${ }^{x x v}$ El 16 de octubre de 1998, el juez Baltasar Garzón dictó una orden de captura contra Pinochet desencadenando el conocido caso. Ese juez había estado investigando crímenes contra españoles durante la última dictadura en Argentina durante dos años. En este sentido, fue un cambio fundamental en el derecho internacional, cambios que se han visto reforzados en las últimas décadas. La protección de los derechos humanos se ha convertido en uno de los principales objetivos de la comunidad internacional. Ese mismo año, en julio, representantes de 120 países se reunieron en la conferencia de Roma para aprobar la propuesta de crear una Corte Penal Internacional, con sede en La Haya, Países Bajos.

xxvi Hubo una pérdida sistemática de votos por parte de los partidos tradicionales, con el consiguiente aumento en la oposición de izquierda. En una elección importante, Tabaré Vázquez fue el candidato más votado en octubre de 1999 (en la primera vuelta), pero no logró la mayoría absoluta de los votos. En la segunda vuelta, en noviembre, perdería ante Batlle. La segunda ronda se estableció a partir de la nueva constitución de 1996.

xxvii La madre de Quinteros, Tota Quinteros, presentó un recurso de amparo por su derecho a acceder a información sobre el destino de su hija. La cámara de apelaciones confirmó la sentencia de la magistrada Jubette. Pero la investigación no tuvo ningún resultado. Pero se había pedido que se reabriera la investigación, sobre la base de la naturaleza civil de Blanco, y éste había acabado siendo condenado, un hecho histórico.

xxviii El Magistrado Reyes fue transferido a un tribunal civil, y el magistrado Alejandro Recarey fue removido en 2003. El magistrado Guayanze también sufrió presiones de transferencia en 2003.

xxix Nicolás Cotugno -quien presidió-, Luis Pérez Aguirre S.J., José D'elia y José Claudio Williman, Gonzalo Fernández y Carlos Ramela Regules y sufrió un único cambio forzado en la integración inicial, la muerte de Luis Pérez Aguirre S.J., siendo sustituido por Jorge Osorio, por la Resolución 486/2001.

xxx En octubre de 2002, la Comisión presentó un informe preliminar que contenía 39 denuncias.

xxxi Según el artículo 1 de la resolución: "Aceptar las conclusiones contenidas en el informe final elevado por la comisión para la paz en el día de la fecha, asumiendo que esas conclusiones constituyen la versión oficial sobre la situación de los detenidos-desaparecidos"

xxxii La izquierda alcanzó su mayor votación y ganó por mayoría absoluta en la primera vuelta. Los partidos tradicionales en conjunto alcanzaron su nivel más bajo y en particular el Partido Colorado, que fue el partido dominante durante décadas, apenas superó el 10\% de los votos (Lanzaro, 2012).

xxxiii La obra de cinco volúmenes contó con varias etapas y renovaciones. La primera se presentó entre mayo y septiembre de 2005. La segunda se presentó en abril de 2009. La tercera, en 2010. El cuarto, hasta el 2011. La última actualización es de 2015 (Rico, 2015: 3). Como indican los informes, en las diferentes etapas las investigaciones fueron más allá de las desapariciones forzadas, investigando torturas, detenciones y otros temas.

xxxiv Si bien la Ley 18.596 de 2009 repara a las víctimas del Terrorismo de Estado su artículo 22 es controvertido, en tanto que define el intercambio de dignidad por dinero: "Se renuncia a toda futura acción contra el Estado uruguayo, ante cualquier jurisdicción, sea ésta nacional, extranjera o internacional, por el solo hecho de acogerse a los beneficios reparatorios de la presente ley" xxxv Se exigía la firma del 10\% (más de aproximadamente 250,000) de los votantes registrados. Se recogieron 337.000 firmas y se presentaron ante el Tribunal Superior Electoral.

xxxvi En diciembre de 2008, el SCJ acepto el ingreso de la causa. El caso de Nibia Sabalsagaray fue iniciado en 2004, por la hermana Stella.

xxxvii Los que están a favor deben poner el Sí en el sobre, y los que no están a favor no deben poner nada. Por lo tanto, los indecisos o sin opinión fueron computados como no.

xxxviii Mujica fue uno de los tupamaros detenidos un año antes de la dictadura militar. Mujica permaneció en duras condiciones de detención durante once años.

xxxix Filippini (2012: 191) lo indica: "La solución es muy discutible para quienes asignan a la democracia mayores exigencias deliberativas. Desde esta visión, el origen de las normas, a diferencia de lo afirmado por la Corte IDH debe tener un peso mayor y el argumento del fallo lo desestima erradamente al clasificarlo únicamente como una cuestión formal". En otra línea, según Gargarella (2015): "la Corte IDH perdió una gran oportunidad para 
contribuir al debate colectivo internacional en torno a temas de primera trascendencia, como los referidos a la democracia, y la legitimidad de las decisiones que resultan del debate público”. La Corte declaró en la sentencia: "que la Ley de Caducidad haya sido aprobada en un régimen democrático y aún ratificada por la ciudadanía en dos ocasiones no le concede automáticamente ni por sí sola legitimidad ante el Derecho Internacional." (CIDH, 2011: 68). En este sentido, Gargarella (2011) señala que "si se me permite exagerar un poco la imagen, la democracia debe arrodillarse frente al Derecho Internacional, que a su vez es interpretado por una elite de personas a las que ni conocemos". Por su parte, para Filippini, la decisión de impunidad en el caso Gelman debe ser analizada en su contexto. La sentencia se inscribe en un contexto fuertemente limitado por la impunidad generalizada de las presiones antidemocráticas desde el principio (Filippini, 2012: 192). ${ }^{x l}$ Se contabiliza desde el 1 de marzo de 1985, fecha oficial del retorno democrático.

xli El 21 de marzo se colocó una placa en honor de María Claudia García, Macarena Gelman y a todas las víctimas que fueron detenidas en el centro de detención clandestino La Mansión. El 4 de junio se realizó un acto público en la sede del Palacio Legislativo donde se entregó el certificado de reconocimiento (documento oficial que acredita la condición de víctima y el reconocimiento del Estado uruguayo por su responsabilidad institucional) (Rico et al, 2014: 134). Entre otras actividades para la memoria y la reparación.

xlii Centro de Estudios Legales y Sociales - CELS (Argentina); Asociación Pro Derechos Humanos (Perú); Observatorio Derechos Humanos, Universidad Diego Portales (Chile).

xliii El Observatorio Luz Ibarburú está integrado por 15 organizaciones sociales -entre ellas Pit-Cnt- y personas jurídicas. En la actualidad, forman parte del órgano rector: PIT/CNT (Secretaria de Derechos Humanos y Políticas Sociales), SERPAJ, Madres y Familiares de Detenidos Desaparecidos, CRYSOL, Mesa Permanente Contra la Impunidad, Fundación Mario Benedetti, Comisión por la Memoria de los Fusilados de Soca, Fundación Zelmar Michelini, Asociación Civil ex-Trabajadores del Diario El Popular (1957-1973), FEUU.

xliv Para tener una dimensión de la importancia en el área específica: en diciembre de 2015, el Equipo patrocinó un total de 44 denuncias que comprenden 236 víctimas. Tomando el número total de causas activas de crímenes de la dictadura como 173, el número de denuncias patrocinadas por EJOLI equivale al 25,5\% del número total de casos judiciales (EJOLI, 2015).

xlv El equipo fue dispuesto en la órbita de la Dirección de asuntos interiores del Ministerio del Interior.

xlvi Alberto Reyes, Estela Jubette, Alejando Recarey y Mirtha Guianze han sido presionados y en algunos casos transferidos como se prescribió anteriormente.

xlvii Muchas organizaciones emitieron comunicados en contra de la resolución del SCJ. Madres y familiares de detenidos desaparecidos, HIJOS, asociación de ex presos políticos Crysol y SERPAJ. Existieron manifestaciones del Canciller Luis Almagro, de la Asociación de Magistrados del Uruguay, del Frente Amplia, de organizaciones latinoamericanas de derechos humanos y de familiares de víctimas, y de sectores de la Universidad de la República (Rico et al, 2014: 137-152)

xlviii La sentencia fue votada por la mayoría de los miembros del SCJ, con disidencia del juez Ricardo Pérez Manrique.

xlix Sentencias de la SCJ 152,186 y 212.

${ }^{1}$ En el mes de octubre de 2015, una operación que duro seis horas, realizó una búsqueda de documentos sobre la dictadura en la causa del fallecido coronel Castiglioni, encontrándose aproximadamente 60 cajas con documentos de la época.

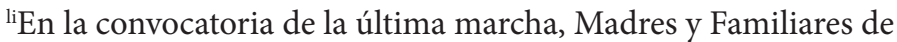
Uruguayos Detenidos Desaparecidos señalaron de forma nítida: "No queremos estas Fuerzas Armadas, ni la impunidad de sus crímenes. Queremos garantías para una democracia plena” Madres y Familiares de Uruguayos Detenidos Desaparecidos. Convocatoria marcha 20 de mayo. 16 de mayo 2019. Recuperado de https://bit.ly/32UZTev

lii El Grupo de Trabajo está integrado por Macarena Gelman, Felipe Michelini, Emilia Carlevaro, Mario Cayota, Ademar Olivera, Pedro Sciofky y Susana Andrade.

liii Gobierno desactiva grupo verdad y justicia y pasara a instituto de DDHH. El Observador. 12 de ag. 2019. Recuperado de https://bit.ly/31MJp6M

liv La unidad está integrada por el Fiscal Ariel Cancela e integrada por la Fiscal Nacional Penal del Quinto Turno Ana María Tellechea, la Fiscal Nacional del Décimo Turno Stella Llorente y la Procuradora General Adscripta Carolina Rico (Presidencia, 2016).

${ }^{\text {lv }}$ La oposición en Uruguay entrega firmas para plebiscitar que FFAA actúen en seguridad pública. Sputnik News, Mundo. 25 feb. 2019. Recuperado de https://bit.ly/2NfkmnC

lvi "Noto un ambiente muy favorable a una mayor participación del Ejército en la seguridad”. Búsqueda, Uruguay. 13 feb. 2019. Recuperado de https://bit.ly/2WjUTNW

lvii Manini Ríos: hay que dejar de hablar de "cosas que ocurrieron hace muchísimo tiempo”. La Diaria, Uruguay. 8 oct. 2019. Recuperado de https://bit.ly/2pb98st

lviii Presidente do Uruguai manda prender chefe militar. Estadão, Brasil. 13 sep. 2019. Recuperado de https://bit.ly/2qRFyIS]

lix Presidente do Uruguai destitui chefe do Exército por suas críticas ao Governo. El Pais, Brasil. 12 mar. 2019. Recuperado de https://bit.ly/2oqQkF9

${ }^{\mathrm{lx}}$ Manini Ríos presenta su candidatura por el Partido Cabildo Abierto. LR21, Uruguay. 3 de abril 2019. Recuperado de https:// bit.ly/2Jusnnu

lxi Feola se negó a repudiar hechos del pasado reciente y luego expresó que no quiso "desconocer la existencia de desaparecidos". La Diaria, Uruguay. 9 de abr. 2019. Recuperado de https://bit. ly/2NkT7Io

lxii Multitudinaria movilización contra la impunidad: “¡Que nos digan dónde están!”. El País, Uruguay. 11 de abr. 2019. Recuperado de https://bit.ly/2PqbU7J

lxii Tribunal italiano condenó a cadena perpetua a militares uruguayos por el Plan Cóndor. Caras\&caretas, Uruguay. 8 de Jul. 2019. Recuperado de https://bit.ly/2MU9JaY

lxiv "Fallo de Roma es el espejo en que debe mirarse el Poder Judicial para salir de la inoperancia”. LR21, Uruguay. 9 de Jul. 2019. Recuperado de https://bit.ly/348iXpK

lxv Comunicado de Prensa. CIDH culmina visita a Uruguay. 31 de mayo de 2019. Recuperado de https://bit.ly/2qTEaFF

lxvi Hasta la fecha se habían encontrado los restos de cinco desaparecidos que fueron debidamente identificados. En 2005 se localizaron en el Batallón 13 los restos del militante comunista Fernando Miranda y en 2006 los del también militante de izquierda Ubagesner Chávez Sosa, mientras que en 2011 se hallaron los del maestro y periodista Julio Castro y en 2012 los del militante comunista Ricardo Blanco. A esto se suma que en 2002 se pudo identificar los restos de Roberto Gomensoro, desaparecido en marzo de 1973, gracias a una prueba de ADN de su cráneo que el forense que había analizado el caso, Emilio Enrique Laca Lanza, se había guardado. Los restos encontrados en el Batallón 13 pertenecen a Eduardo Bleier Horovitz. El País, Uruguay. 7 de Oct. 2019. Recuperado de https://bit.ly/2onM216

lxvii Una multitud despide a Eduardo Bleier en el Paraninfo de la 
Udelar. La Diaria, Uruguay. 14 de Oct. 2019. Recuperado de https://bit.ly/32VF1DE

lxviii Ver Causa 2-110255/2011 Recuperado de https://bit.ly/32R-

$\mathrm{JMhO}$

lxix Ex militar Asencio Lucero procesado con prisión por reiterados delitos de privación de libertad. LR21, Uruguay. 13 de abril 2016. Recuperado de https://bit.ly/2qN0wsc

lxx Torturas y violaciones; fiscal Perciballe pidió procesar a tres militares. La República, Uruguay. 8 de feb. 2019. Recuperado de https://bit.ly/32V0ywu 